WHOI-83-19

\title{
HIGH FREQUENCY BOTTOM STRESS VARIABILITY AND ITS PREDICTION IN THE CODE REGION
}

by

\author{
William D. Grant, Albert J. Williams, 3rd \\ Scott M. Glenn, David A. Cacchione, \\ and \\ David E. Drake
}

\section{WOODS HOLE OCEANOGRAPHIC INSTITUTION \\ Woods Hole, Massachusetts 02543}

June 1983

WHOI Technical Report 83-19
CODE Technical Report No. 15

Prepared for the National Science Foundation under Grant OCE 80-14938.

Reproduction in whole or in part is permitted for any purpose of the United States Government. This report should be cited as: Woods Hole Oceanog. Inst. Tech. Rept. WHOI-83-19.

Approved for Distribution:

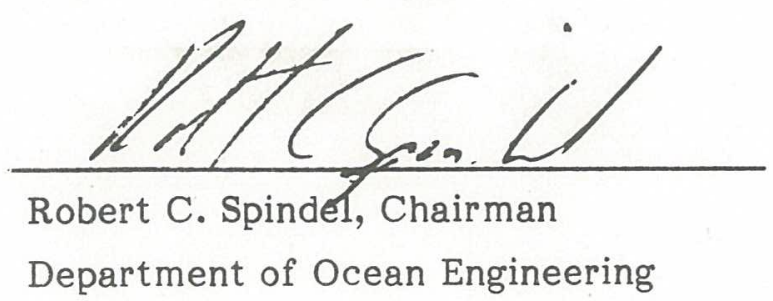



PAGE NO.

ABSTRACT

INTRODUCTION

BOTTOM BOUNDARY LAYER/BOTTOM STRESS COMPONENT

BACKGROUND

EXPERIMENTAL DETAILS

6

a. Site and Flow Description 6

b. Instrumentation and Measurements 9

1. Near bottom velocity measurements: 9

2. Support measurements: 10

c. Data Analysis 13

1. Selection: 13

2. Processing of velocity data: 13

3. Profile analysis: 16

4. Stress and roughness estimates: 17

$\begin{array}{ll}\text { RESULTS } & 20\end{array}$

DISCUSSION 33

a. Measurements 33

b. Comparison with Combined Wave and Current Models 38

1. Theoretical model: 38

2. Comparison with CODE-1 results: 44 


\section{TABLE OF CONTENTS (cont.)}

CODE WINTER STORM DATA

PAGE NO.

EXPERIMENTAL SUMMARY

a. Site and Flow Description, Measurements

b. Processing of Data

1. Selection:

2. Processing data:

3. Profile analysis, stress and roughness estimates:

RESULTS

DISCUSSION

a. Model Calculations

57

b. Comparison with Model

REFERENCES 


\section{LIST OF FIGURES}

PAGE NO.

FIGURE 1: Schematic of CODE-1 small scale array

FIGURE 2: 15 hour record of near bottom flow at $21 / 2$ meters above the bottom at C3 (90 meters of water) during CODE-1 starting approximately $2000 \mathrm{hrs}$. June 2, 1981

FIGURE 3: Horizontal velocity density spectra (10 degrees of freedom)

FIGURE 4: Horizontal velocity density spectra (54 degrees of freedom)

FIGURE 5: Bottom pressure record (2 meters above bottom)

FIGURE 6: Vertical velocity density spectra $\left(w^{\prime}\right)$ (54 degrees of freedom)

FIGURE 7: Velocity profiles $a, h, j$ and 1 from Figure 2

FIGURE 8: Mean velocity profile (averaged over 20.5 minutes, covering profile $d$ and e) for the time period covered by the power spectra plotted in Figures 6 and 9 .

FIGURE 9: Vertical velocity spectral density showing inertial subrange for the 20.5 minute time period in Figure 8

FIGURE 10: 95 percent confidence interval from profiles 
PAGE NO.

TABLE 1: Tripod Measurements and Boundary Layer Support Measurements

TABLE 2: CODE-1 BASS-W Data

TABLE 3: Winter Storm - GEOPROBE Data

TABLE 4: Empirical Relationships for Ripple Geometry

under waves 


\section{ABSTRACT}

High quality bottom boundary layer measurements obtained in the CODE region off Northern California are described. Bottom tripod velocity measurements and supporting data obtained during typical spring and early summer conditions and during a winter storm are analyzed to obtain both velocity profiles and mean bottom stress and bottom roughness estimates. The spring/summer measurements were taken in June, 1981 during CODE-1 at C3 (90 m) by Grant and Williams, WHOI; the winter storm data was taken in November 1980 prior to CODE-1 at the R2 $(80 \mathrm{~m})$ site by Cacchione and Drake, USGS.

The mean near-bottom $(<2 m)$ velocity profiles are logarithmic $\left(R^{2}>0.993\right)$ much of the time for everyday flows; deviations are primarily due to kinematical effects induced by unsteadiness from internal waves. Stress profiles show the logarithmic layer corresponds to a constant stress layer as expected for the inertial region of a boundary layer. Stress estimates made from dissipation and profile techniques agree at the 95 percent confidence level. Typical $z_{0}$ values estimated from measurements greater than $30 \mathrm{~cm}$ above the bottom have magnitudes of approximately $1 \mathrm{~cm}$; an order of magnitude larger than the physical bottom roughness. Corresponding $u_{\star}$ values have typical magnitudes of $0.5-1.0 \mathrm{~cm} / \mathrm{sec}$; more than twice as large as expected from a usual drag law prediction (corresponding to over a factor of four in mean stress). These values are demonstrated to be consistent with those expected for combined wave and current flows predicted theoretically by Grant and Madsen (1979) and Smith (1977). The $u_{*}$ values estimated from the CODE-1 data and predicted by the Grant and Madsen (1979) model typically agree within 10-15 percent. Similar results are demonstrated for the winter storm conditions during which large sediment transport occurs. (Typical $z_{0}$ values are $4-6 \mathrm{~cm}$; typical $u_{*}$ values are $3-6 \mathrm{~cm} / \mathrm{sec}$ ).

The waves influencing the mid-shelf bottom stress estimates are 14-20 second swell associated with Southern and Western Pacific storms. These waves are present over most of the year. The results clearly demonstrate that waves must be taken into account in predicting bottom stress over the Northern California Shelf. 


\section{INTRODUCTION}

BOTTOM BOUNDARY LAYER/BOTTOM STRESS COMPONENT OF CODE

The bottom boundary layer and bottom stress component of the Coastal Ocean Dynamics Experiment, CODE (see Allen et al, 1982 for a description of the CODE-1 Experiment), has as two of its primary objectives in CODE-1: (1) the resolution of the bottom stress on the shelf to determine the key physical processes influencing its magnitude and spatial and temporal variability; and (2) the development of an appropriate model for prediction of stress and the associated near bottom velocity profile from easily measured variables for the flow and bottom conditions. The experimental program enacted to carry out these objectives was composed of two current measurement programs, a 1 ong term, sparsely sampled component and a short term, densely sampled component, along with a detailed survey effort to characterize the micro- and macrophysiography of the continental shelf in the CODE area.

The long term component consisted of the deployment of a single USGS GEOPROBE tripod at a mid-shelf 1ocation in the CODE-1 array for time periods of two to three months. This tripod measured velocity profiles for 272 seconds every two hours along with a suite of supporting variables. These measurements are being analyzed to yield a long time series of stress which reflects its time variability and the relative variability of the processes contributing to the stress. The long term component was maintained for the better part of one year during CODE and approximately 15 months prior to CODE.

A short term (approximately two weeks in CODE-1) experiment was nested within this long term monitoring program. The goal of this short term experiment was to provide detailed measurements of the relevant variables required to resolve the role of key processes contributing to the bottom stress magnitude and its temporal and spatial variability, and to make accurate 
estimates of vertical profiles of stress and near bottom horizontal velocity. These measurements allow us to determine the applicability of the profile technique used to make stress estimates from the 1 ong term measurements. They also provide a highly accurate data set from which to test models for bottom velocity profile and stress prediction from knowledge of several easily measured variables. The short term experiments also were used to examine the spatial variability of the bottom stress field on a local scale of hundreds of meters and on a larger scale, in the cross shelf direction. The short term component consisted of an array of WHOI BASS W bottom tripods deployed for periods of 3-5 days. These tripods sampled a suite of variables and 3-components of velocity at 4 levels above the seabed using a repeating sequence of continuous measurements for up to several hours and a shut off period of approximately an hour.

This report presents results on the mean and surface wave components of the flow field and associated stress estimates. Here the term mean refers to time averages over 10 to 20 minutes. The reasons for this interpretation are discussed in detail in the report. It addresses in detail only the prediction of the velocity profile and mean stress at a point on the shelf as a function of the processes occurring there. The description of the overall bottom boundary layer structure, the large scale spatial and 1ong term temporal variability in the bottom stress, turbulent structure, and the general description of the stress field on the shelf will be addressed in future papers and reports. The key motivation here is to establish the ability to predict accurately the velocity profile and stress at a point as a function of the key processes occurring there. This ability allows one to look at the variability in these processes across the shelf and predict the associated variability in stress rather than having to make detailed measurements at each point on the shelf from which stress can be directly estimated. 
BACKGROUND

Numerous observations of bottom flows on the continental shelf, including the CODE site, demonstrate that typically, the near bottom flow field is composed of velocity components due to both surface waves and 1 ow frequency currents (tidally, wind, or density driven). Other phenomena occurring on the shelf which have the potential to influence the near bottom flow structure include: (1) stratification due to temperature and salinity, (2) stratification due to suspended sediment, (3) moveable bed effects (i.e., ripples and near bed sediment transport, bioturbation), (4) internal waves and (5) topographically complex bottoms.

Several of the above phenomena have somewhat similar effects on the mean velocity profile. For example, both surface waves and moveable bed phenomena affect the roughness felt by the flow measured 10's of centimeters above the bottom. In both cases, the roughness length is increased by an order of magnitude or more over the roughness attributed to the sediment grain size. Failure to correct measured near bottom velocity profiles for stratification effects leads to an erroneous increase in the boundary roughness and in the value of von Karman's constant, (Grant and Glenn, 1983). The presence of higher frequency internal waves superimposed on a mean flow results in an apparent "kink" or change in slope in the velocity profile, both of which can look similar to the effects of upstream topography. Moreover, at any time several of the above phenomena may be present and affect the flow simultaneously causing significant changes to the slope of the measured mean velocity profile near the bed.

Thus, in carrying out a bottom boundary layer experiment it is of utmost importance to make measurements which allow unambiguous and quantitative 
assessment of the phenomena causing the observed velocity structure and affecting the associated estimated quantities such as velocity profile distributions and bottom stress. To distinguish between various phenomena present, the important variables to characterize a particular process and how well they must be measured have to be identified. For this task, theoretical models of the various phenomena are useful. Theoretical models for the near bottom flow field and bottom shear stress under combined wave and current flows have been developed by Grant and Madsen (1979) and Smith (1977). Both of these models include non-linear interaction between the wave and current flows and give solutions for the wave and current kinematics and associated boundary shear stress. Each model partitions the bottom boundary layer into two distinct boundary layer regions. A wave boundary layer region, limited in vertical extent by its short diffusion time scale, is nested within a larger mean flow boundary layer. These models predict, for the combined flow over rough bottoms, that the mean shear stress above the wave boundary layer is enhanced by the presence of the waves. The Grant and Madsen (1979) model-also predicts that the flow above the wave boundary layer "feels" an increased roughness, termed an apparent roughness. This apparent roughness depends on the characteristics of the turbulent wave boundary layer as well as the physical bottom roughness associated with moveable bed effects (e.g., bedforms or sediment transport, or animal mounds).

The Grant and Madsen (1979) model recently has been extended to include the phenomena (1)-(3) above; (Grant and Madsen, 1982; Glenn, 1983; Grant and Glenn, 1983). The results of the extensions indicate that the inclusion of flow-sediment interaction through moveable bed effects and self-stratification of the near bottom flow by suspended sediment have pronounced and important 
influences on the near bottom velocity profile; these influences are likely to be most important during storm flows. Thus, it is highly desirable to have data over a variety of conditions corresponding to situations (1) where wave and current interaction only is the major process, and (2) where the wave and current interaction is occurring with sediment transport.

Qualitative agreement with the predictions of the model of mean shear stress, roughness and mean velocity profiles (above the wave boundary 1ayer) are available from field measurements by Cacchione and Drake (1982) and from laboratory measurements by Bakker and Van Doorn (1978) and Kemp and Simons (1981). Although these measurements provide encouraging agreement with the models, none of these data sets contain the required control for an unambiguous test of the model $s^{1}$. This report provides direct observations of the key processes contributing to the bottom stress and also provides a quantitative and unambiguous comparison of the near bottom flow and stress models with high quality data sets.

Two data sets have been picked for comparison with the Grant and Madsen (1979) model. Both were taken at the CODE sites on the northern California Continental Shelf. The two data sets cover conditions from strong wind forcing (25-40 knt. winds) to storm conditions, and therefore allow a test of the model over a range of important conditions from combined waves and currents with no strong sediment interaction to the combined flow-sediment case. The first data set, designated CODE-1, corresponds to the case of strong wind forcing and

1. A reanalysis of the GEOPROBE storm data taken in the Norton Sound (Cacchione and Drake, 1982) by Wiberg and Smith (in press) show that by making zero shifts of the velocity profiles, better agreement is achieved with roughness length estimates from theories of Grant and Madsen (1979) and Smith (1977). The data quality is still limited by the one minute record lengths, however. 
contains detailed support measurements and flow measurements covering frequencies from inertial periods up through small scale turbulence. The data set allows resolution of the contributions of the various processes which can influence the near bottom flow. The second data set, designated pre-CODE Winter Storm, is less detailed and has fewer (but adequate) support measurements; it covers flow conditions corresponding to the strong wind forcing of the CODE-1 data and includes a storm passage. The CODE-1 data are from measurements made by the Woods Hole Oceanographic Institution bottom boundary layer group (Grant and Williams) and the Winter Storm data are from measurements made by the sediment processes group, USGS, Men1 o Park, CA (Cacchione and Drake).

\section{CODE-1 DATA}

\section{EXPERIMENTAL DETAILS}

\section{a. Site and Flow Description}

The CODE site is located along the Northern California shelf between Point Arena and Point Reyes. The measurements described here were made during CODE-1 in early June, 1981 in approximately 100 meters of water at the vicinity of station $\mathrm{C} 3\left(38^{\circ} 37.2^{\prime} \mathrm{N}, 123^{\circ} 28.4^{\prime} \mathrm{W}\right)$ along the central line of the small scale CODE-1 array (see Figure 1). The prevailing winds along the northern California coast during late spring and summer are from the northwest and are upwelling favorable. The wind speed is highly variable and over the middle and inner shelf there is pronounced diurnal variability in the longshore wind caused by the 1ocal sea breeze. The wind during the CODE-1 Bottom Boundary Layer/Bottom Stress cruise was consistent with this prevailing wind pattern with speeds of 25-40 knots out of the north-northwest. During the experiments, the mean near bottom flow exhibited considerable variability in magnitude and 


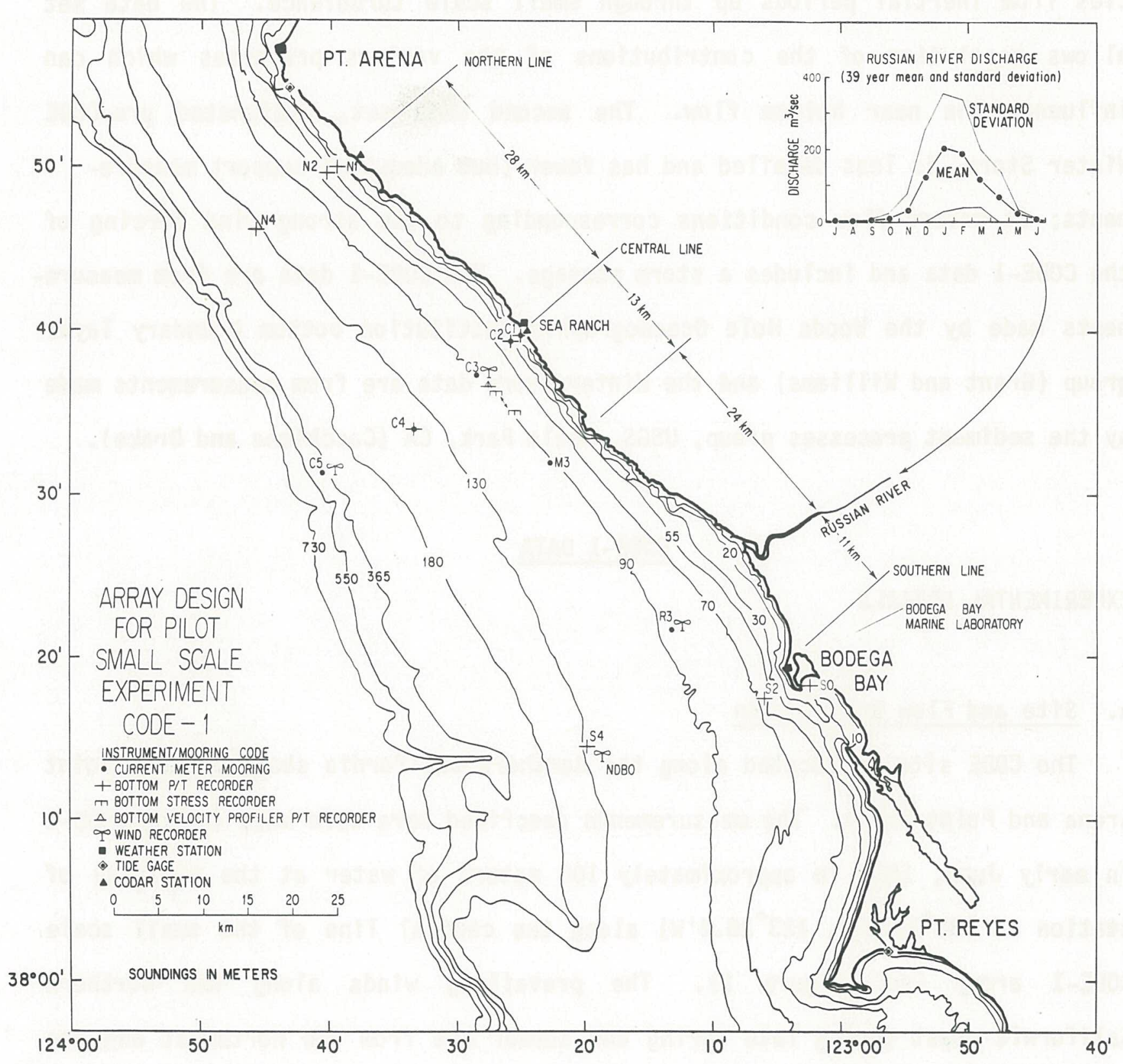

Figure 1: Locations of the principal CODE-1 mooring sites along north (N), central (C) and south (S) cross-shelf transects. 


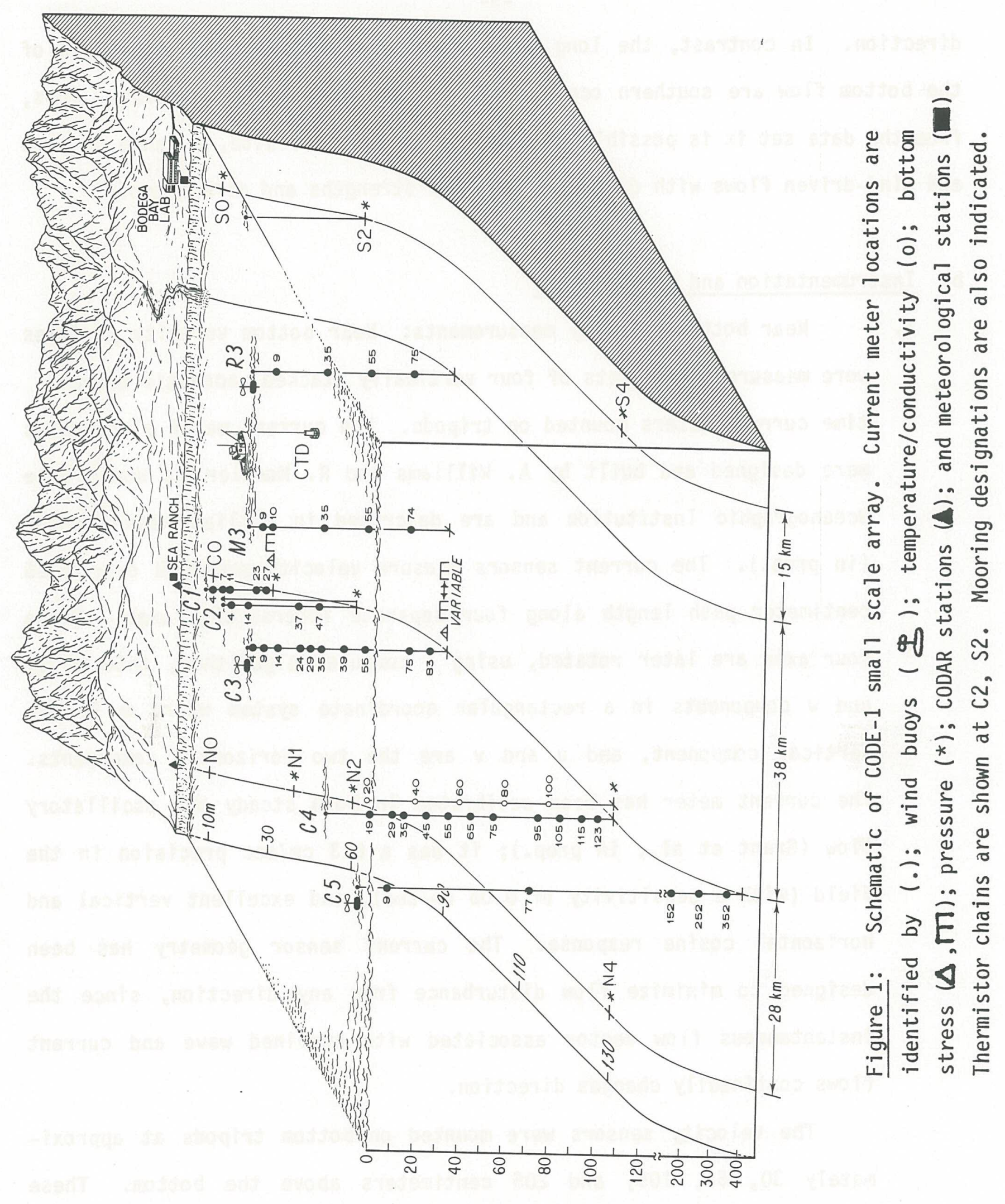

(ii) $H \perp d \exists O$ 
direction. In contrast, the long waves driving the oscillatory component of the bottom flow are southern ocean swell and are relatively constant. Thus, from the data set it is possible to examine, at the same site, a range of wave and wind-driven flows with differing relative strengths and directions.

\section{b. Instrumentation and Measurements}

1. Near bottom velocity measurements: Near bottom velocity profiles were measured using sets of four vertically stacked, acoustic travel time current meters mounted on tripods. The current meter electronics were designed and built by A. Williams and R. Koehler at Woods Hole Oceanographic Institution and are described in Williams and Koehler (in prep.). The current sensors measure velocity averaged over a 15 centimeter path length along four separate intersecting axes. These four axes are later rotated, using a computer algorithum, into $u$, v, and $w$ components in a rectangular coordinate system where $w$ is the vertical component, and $u$ and $v$ are the two horizontal components. The current meter has been calibrated in both steady and oscillatory flow (Grant et al., in prep.); it has a $0.3 \mathrm{~cm} / \mathrm{sec}$ precision in the field (with a sensitivity of $0.06 \mathrm{~cm} / \mathrm{sec}$ ), and excellent vertical and horizontal cosine response. The current sensor geometry has been designed to minimize flow disturbance from any direction, since the instantaneous flow vector associated with combined wave and current flows continually changes direction.

The velocity sensors were mounted on bottom tripods at approximately 30, 55, 105, and 205 centimeters above the bottom. These actual heights were later corrected for tripod settlement into the 
bottom as monitored by a mechanical gauge or $1 \mathrm{Mhz}$ echo sounder. In addition to the velocity sensors, the tripods contained instruments to monitor variables required in the analysis and interpretation of the velocity data. These instruments and their locations relative to the bottom are described below and listed in Table 1 along with a summary of the velocity sensors.

Two different sampling schemes on two different tripods were employed during the experiment because of the interest in making both a large number of measurements at fast sampling rates and 1 ong term measurements. One tripod sampled at $5 \mathrm{hz}$ and telemetered data back to the ship. This fast-sampling tripod employed a variable length sampling duration controlled from the ship; typically 60 to 120 minutes on and 40 minutes off. A second tripod contained less support instruments and sampled at $2 \mathrm{hz}$; this tripod recorded in situ for up to six hours. For the mean flow speeds observed and the averaging volume of the sensors, the measurements on both tripods extended into the frequency band of the inertial subrange.

2. Support measurements: A pressure sensor (Paroscientific digiquartz), compass, pitch and roll sensors, and three thermistors were mounted on all tripods (Table 1). The pressure sensors were used to determine both water depth and as an independent measure of the surface waves. The thermistors were used in conjunction with CTD profiles to monitor possible near bottom stratification and changes in temperature associated with advection of bottom water. Pitch and roll sensors were used to monitor tripod orientation relative to the bottom and to monitor any settlement. The telemetering tripod also contained 
TABLE 1: Tripod Measurements and Boundary Layer Support Measurements

\begin{tabular}{|c|c|c|c|}
\hline Sensor & $\begin{array}{l}\text { Measurement/ } \\
\text { Parameters }\end{array}$ & Location & Sampling rate \\
\hline $\begin{array}{l}\text { Acoustic travel } \\
\text { time current } \\
\text { meter ( } 15 \mathrm{~cm} \\
\text { averaging volume) }\end{array}$ & $u, v, w$ & $\begin{array}{l}30,55,105 \\
205 \mathrm{~cm} \text { tripod }\end{array}$ & $5 \mathrm{hz}$ \\
\hline Pressure & $\begin{array}{l}\text { pressure/ } \\
H, T, h, u_{W}, v_{W}\end{array}$ & $\begin{array}{l}105 \mathrm{~cm} \\
\text { tripod }\end{array}$ & $5 \mathrm{hz}$ \\
\hline $\begin{array}{l}\text { Transmissometer } \\
\text { (1/4 meter) }\end{array}$ & $\begin{array}{l}\text { light attenuation/ } \\
\text { total suspended } \\
\text { concentration }\end{array}$ & $\begin{array}{l}75 \mathrm{~cm}, 175 \mathrm{~cm} \\
\text { tripod }\end{array}$ & $5 \mathrm{hz}$ \\
\hline Thermistors & temperature $\left(T^{\circ}\right)$ & $\begin{array}{l}50,100,200 \mathrm{~cm} \\
\text { tripod }\end{array}$ & $5 \mathrm{hz}$ \\
\hline Compass & direction & $\begin{array}{l}21 / 2 \mathrm{~m} \\
\text { tripod }\end{array}$ & $5 \mathrm{hz}$ \\
\hline Pitch/Roll & tripod tilt & $\begin{array}{l}21 / 2 \mathrm{~m} \\
\text { tripod }\end{array}$ & $5 \mathrm{hz}$ \\
\hline $\begin{array}{l}\text { Bottom locator } \\
\text { (mechanical or } \\
\text { acoustic } 1 \text { Mhz) }\end{array}$ & bottom location & $\begin{array}{l}\text { bottom } \\
\text { tripod }\end{array}$ & $\begin{array}{l}N / A \\
1 / \sec \end{array}$ \\
\hline Camera & bottom photograph & tripod & $1 /$ half hour \\
\hline $\begin{array}{l}\text { Vector measuring } \\
\text { Current meter }\end{array}$ & $u, v, T^{0}$ & 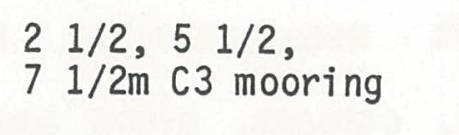 & $\begin{array}{l}\text { vector averaged } \\
\text { every } 4 \text { minutes }\end{array}$ \\
\hline $\begin{array}{l}\text { CTD } \\
\text { (NBIS) } \\
\text { (SCIMP) }\end{array}$ & $\begin{array}{l}\text { conductivity } \\
\text { temperature } \\
\text { pressure }\end{array}$ & $\begin{array}{l}\text { surface to within } \\
1 / 2 \text { meter off bottom } \\
\text { CODE site }\end{array}$ & selected intervals \\
\hline Side Scan & bottom topography & CODE site & selected intervals \\
\hline Box Cores & $\begin{array}{l}\text { bottom topography } \\
\text { benthic biota, } \\
\text { sediment }\end{array}$ & CODE site & selected intervals \\
\hline Suspended Sediment & $\begin{array}{l}\text { water samples } \\
\text { sediment } \\
\text { concentration }\end{array}$ & CODE site & selected intervals \\
\hline
\end{tabular}


two transmissometers (Sea Tech; $1 / 4$ meter path 1ength) to monitor suspended sediment concentration. All instruments on the tripods were sampled simultaneously with the velocity sensors. Over the course of the experiments CTD profiles within 0.5 meters of the bottom were systematically taken at tripod locations to determine the location of the bottom mixed layer and possible stratification of the bottom boundary 1ayer.

Geological and biological data were collected during CODE-1 and other cruises in the region. Bottom topography was measured so that macro- and micro-topography could be determined in the vicinity of the tripod locations. Side scan sonar tracks were run to resolve large scale features relative to the tripod location. Bottom cameras and box cores were used to resolve the micro-topography and to sample the benthic biota responsible for generating the micro-topography. The results of these latter measurements are reported in Cacchione et al. (1983). The bottom sediment distribution at the site was mapped using tripod samples, grab samples, and box cores. The distribution also is summarized in Cacchione et a1. (1983). Water samples taken during hydrographic transects allowed the suspended sediment to be related to the bottom sediments and the transmissometer measurements.

Low frequency characteristics of the flow, internal waves, and vertical profiles of velocity through the bottom boundary layer were determined from measurements made using arrays of vector measuring current meters (VMCM's) deployed at the CODE site. In CODE-1, during the boundary layer experiments, a densely spaced (in the vertical) current meter mooring was deployed by $C$. Winant and $R$. Davis in 90 
meters of water at C3, with VMCM's at 7, 15, 35, 51, 55, 61 and 66 meters above the bottom, and 14, 9 and 4 meters below the surface (Allen et a1., 1982). During the short term bottom stress experiments

a near bottom mooring was deployed with VMCM's at $2.5,5.5$, and 7.5 meters. This mooring was designed to provide continuity between the tripod measurements and the large VMCM array. Temperature was also measured in the large VMCM array.

\section{c. Data Analysis}

1. Selection: Approximately 4 days of high frequency boundary layer data was taken at $\mathrm{C} 3$ during the CODE-1 experiment. In addition, three simultaneous deployments of two tripods at $C 3$ within a kilometer of each other, provide replicate data on the near bottom flow. Measurements from the telemetering ( $5 \mathrm{~Hz}$ sampling rate) tripod during a typical 15 hour time period have been selected here for detailed analysis and comparison with model predictions. During this time period data quality is high and adequate support measurements are available.

2. Processing of velocity data: The velocity data from each travel time axis on the acoustic current meters is recorded on cassette tape. This data is unpacked onto 9 track tape, each axis is wild point edited and the calibrated offset for each axis is subtracted out. The data from each axis is rotated into a standard streamline turbulent velocity system such that

$$
\vec{u}=\left(u+u^{\prime} ; v^{\prime} ; w^{\prime}\right)
$$


where $u$ is the mean downstream velocity, $u^{\prime}, v^{\prime}$, are the fluctuating components of velocity in the stream-wise and cross-stream directions respectively, and $W^{\prime}$ is the fluctuating component of velocity normal to the streamline.

The magnitude of the mean velocity is defined as

$$
u=\frac{1}{T}\left|\int_{t}^{t+T} \vec{u}(t) d t\right|
$$

where $T$ is the averaging time. Spectral analysis of the resulting velocity signal demonstrates that it is composed of fluctuations associated with high frequency turbulence, surface waves, internal waves, and low frequency shelf currents. Thus, in (2) $T$ is chosen to be 1 onger than the surface wave period but significantly less than the internal wave period. The characteristics of the internal waves and surface waves are best determined from measurements independent of the tripod velocity records since the latter measurements contain contributions from the full range of frequencies present.

The surface wave period and velocity were calculated independently from the velocity measurements by using the pressure signal. Linear wave theory was used to convert the pressure records to the equivalent bottom velocity. Extensive comparisons made between one dimensional wave spectra based on the measured velocity from the current meters and the velocity calculated from the pressure records using linear theory demonstrate that the two techniques yield nearly identical results. Wave period was determined by keeping track of zero crossings in the pressure record. Wave direction was determined using the pressure sensor and the two horizontal velocity components at the same 
height. These measurements were fitted to a directional wave model (e.g., Borgman, 1976; Nagata, 1964) using a wrapped normal distribution for the spreading function. Although the vertical velocity could be substituted for pressure in these directional wave calculations, the pressure is preferred because of its superior signal-to-noise ratio relative to the vertical velocity records.

The internal waves are more difficult to quantify on a wave by wave basis. However, detailed analysis of velocity and temperature records from VMCM's located just above the bottom mixed layer shows the existence of individual wave packets propagating onto the shelf. These packets are intermittent; their presence is readily determined from the temperature records and the period of individual waves can be determined approximately from the temperature fluctuations.

The turbulent contribution to the velocity signal at high frequencies can be resolved from the three axis acoustic current meter measurements. The current meters are capable of measuring well into the inertial subrange for the flow speeds observed and the sampling rate used; the high wave number cut off in resolution is set by the averaging volume of the sensors.

To investigate whether a subrange exists the spectral density for the velocity components in the turbulent coordinate system corresponding to (1) is explored. Frequency can be converted to wave number by applying a frozen turbulence assumption. This assumption requires $u^{\prime} / u \ll 1$ (Lumley, 1965) and therefore must be used with care in frequency bands where large velocity fluctuations are associated with surface waves. Moreover, Lumley et a1. (1982) and Donelan et al. 
(1982), in studies of the marine surface layer, have found that the entire subrange behavior may be affected when large orbital wave velocities are present. To minimize contamination of the spectrum from kinematical effects associated with orbital wave velocities and to use the frozen turbulence approximation, only $w^{\prime}$ spectral density estimates are used since vertical wave orbital velocities are much much less than the mean velocity in the bottom two meters.

3. Profile analysis: The time averaged near bottom velocity profile in a neutral, turbulent Ekman 1ayer over a topographically simple bottom, characteristic of the CODE site, is predicted to follow a logarithmic velocity profile given by

$$
u=\frac{u_{\star}}{k} \ln \frac{z-\delta_{D}}{z_{0}}
$$

where $u$ is the mean horizontal velocity, $k$ is von Karmans constant, $z$ is the height above the bottom, $z_{0}$ is the bottom roughness, $\delta_{D}$ is the displacement thickness and $u_{*}$ is the shear velocity associated with the mean flow; $u_{\star}=\sqrt{\tau_{c} / \rho}$ where $\tau_{c}$ is the magnitude of the time averaged bottom stress and $\rho$ is the fluid density.

The processed velocity time series were first time averaged over intervals of approximately 5, 10, 15, and 20 minutes using a running average. The resulting velocity averages were plotted on a semilogarithmic scale and the best fit straight line using a least squares linear regression was fitted to the plotted points for comparison with (3).

The flow must be referenced to the average bottom location around the tripod, not simply the bottom at the point below the velocity 
sensor. A rough estimate of the maximum uncertainty in the relative vertical position of the bottom location for these experiments is about 5 centimeters. This estimate is arrived at by considering the standard deviation of all the bottom location measurements (mechanical gauge and 1 Mhz echo sounder), taking into account the resolution of the side scan and the heights of the micro-topographic features estimated from bottom photos and box cores. Thus, the velocity measurements were shifted upward and downward (referred to as zero shifts) within the range of the $5 \mathrm{~cm}$ resolution to look at the sensitivity of the profiles to zero shifts and to remove any curvature in the profiles. Corrections for displacement thickness, estimated from the roughness element heights (Jackson, 1981) were also applied. After appropriate zero shifts and time averages were applied, profiles passing a set criteria were picked for more detailed analysis to determine bottom stress and roughness. The selection criteria specified that (1) no curvature was present in the profiles and (2) a regression coefficient squared for the best least squares fit to a logarithmic profile exceed 0.993. These criteria were set to minimize error bars in stress estimates made using the velocity profile technique. These error estimates are described below.

4. Stress and roughness estimates: Bottom stress and the stress at the upper 3 levels in the profile where velocity was measured, were estimated using the inertial dissipation technique, (Deacon, 1959). Estimates of stress were made using this technique for three reasons. First, it provides an independent technique for estimating stress and 
roughness which is relatively insensitive to zero shifts or other adjustments which are often necessary when using the velocity profile technique and therefore acts as a check on the profile estimates. Secondly, the presence of a logarithmic profile assumes the presence of a constant stress region near the boundary; it is important to be able to check this assumption. Thirdly, the velocity profile over the full two meters may not be described by a single logarithmic profile. Thus, with only four velocity measurements the profile technique cannot be used accurately and dissipation estimates provide the stress values.

The inertial dissipation technique utilizes the relationship between the kinetic energy density and wave number in the inertial subrange to calculate the stress. In a neutral, locally isotropic, horizontally homogeneous and stationary boundary layer, the onedimensional kinetic energy density $\phi(k)$ can be expressed in terms of the dissipation $\varepsilon$ as

$$
\phi_{w}(k)=\alpha \varepsilon^{2 / 3} k^{-5 / 3}
$$

where $k$ is the wave number $(=2 \pi / L)$, and $\alpha$ is the Kolmogorov constant, normally taken as $0.5 . \phi_{W}(k)$ is defined in terms of the spectral density in frequency as

$$
\phi_{w}(k)=\frac{\phi^{\prime}(f)}{\frac{2 \pi}{u}}
$$

where $b^{\prime}(f)=S(f) / \Delta f$ in which $S(f)$ is the power spectrum and $\Delta f$ is the band width. The factor of two is included in (5) to make $\phi_{w}(k)$ equivalent to kinetic energy. The frozen turbulence hypothesis has been used to convert frequency to wave number. The turbulent kinetic 
energy balance assumes that dissipation equals production of energy under these conditions. Thus, $\varepsilon=-\overline{u^{\prime} w^{\prime}} \partial u / \partial z$. If the region is near the bottom and is a constant stress layer $-\overline{u^{\prime} w^{\prime}}=u_{*}^{2}$ and $u_{*}^{2}$ can be expressed in terms of the dissipation, $\varepsilon$, as

$$
u_{\star}^{2}=\left(\begin{array}{lll}
k & z
\end{array}\right)^{2 / 3}
$$

Rearranging (4) allows $\varepsilon$ to be expressed in terms of the spectral density function $\phi(k)$. Substituting this result in (6) gives an expression for $u_{*}$ in terms of $\phi(k)$

$$
u_{*}=\left\{\left[\frac{\phi(k) k^{5 / 3}}{\alpha}\right]^{3 / 2} \kappa z\right\}^{1 / 3}
$$

Bottom stress and bottom roughness were estimated also from the measured velocity profiles. The velocity profiles used to make stress estimates were selected based on the previously mentioned criteria $\left(R^{2}>0.993\right)$, but only after demonstrating correspondence between dissipation estimates and profile estimates of stress. The velocity profile given by (3) can be rewritten in the form

$$
\log \left(z-\delta_{D}\right)=\frac{k}{2.3 u_{\star}} u+\log z_{0}
$$

which is the equation for a straight line on a plot of $10 \mathrm{~g}\left(z-\delta_{D}\right)$ versus $u$. The shear velocity is determined from the slope of the line and the roughness length from the $z$ intercept. For the current meter configuration used in these experiments the minimum $R^{2}$ value corresponds to a 95 percent confidence interval of \pm 25 percent on $u_{*}$ estimates from velocity profiles. The majority of the profiles have $\mathrm{R}^{2}$ greater than 0.996 which corresponds to a 95 percent confidence interval of \pm 18 percent on $u_{*}$. 
RESULTS

A time series of mean flow speed and direction at 2.5 meters above the bottom during a 15 hour interval in CODE-1 on June 2-3, 1981, is plotted in Figure 2. The mean flow direction changes from northward along-shelf flow, to westward cross-shelf flow, and then back to northward again. The speed decreases as the flow becomes westward and increases again as the flow returns to the north. The velocity range is from $10 \mathrm{~cm} / \mathrm{sec}$ to $16 \mathrm{~cm} / \mathrm{sec}$.

A 1 ook at the distribution of the near bottom kinetic energy with frequency provides a convenient description of the dynamical processes driving the flow and contributing to its variability. The low frequency variability between 0.001 and $0.8 \mathrm{cpm}$ is illustrated in the velocity spectra in Figure 3 . The flow is forced at several discrete frequencies; a peak is evident below the semidiurnal tidal frequency ( $0.0014 \mathrm{cpm})$; between tidal and Brunt Vaisala frequencies ( 0.05 (pm), several discrete peaks are evident which are an order of magnitude less energetic. Cross spectral analysis between on-shore, off-shore velocity components measured by VMCM current meters at 5.5 and 7.5 meters on the same mooring indicates high coherence and zero phase at these frequencies; behavior consistent with the presence of internal waves as was indicated by the temperature records.

The characteristics of the internal waves present during the time period covered by Figure 3 are not evident from the spectral analysis. Analysis of the temporal vertical variation of individual isotherms at the top of the bottom mixed layer, shows the internal waves propagate 

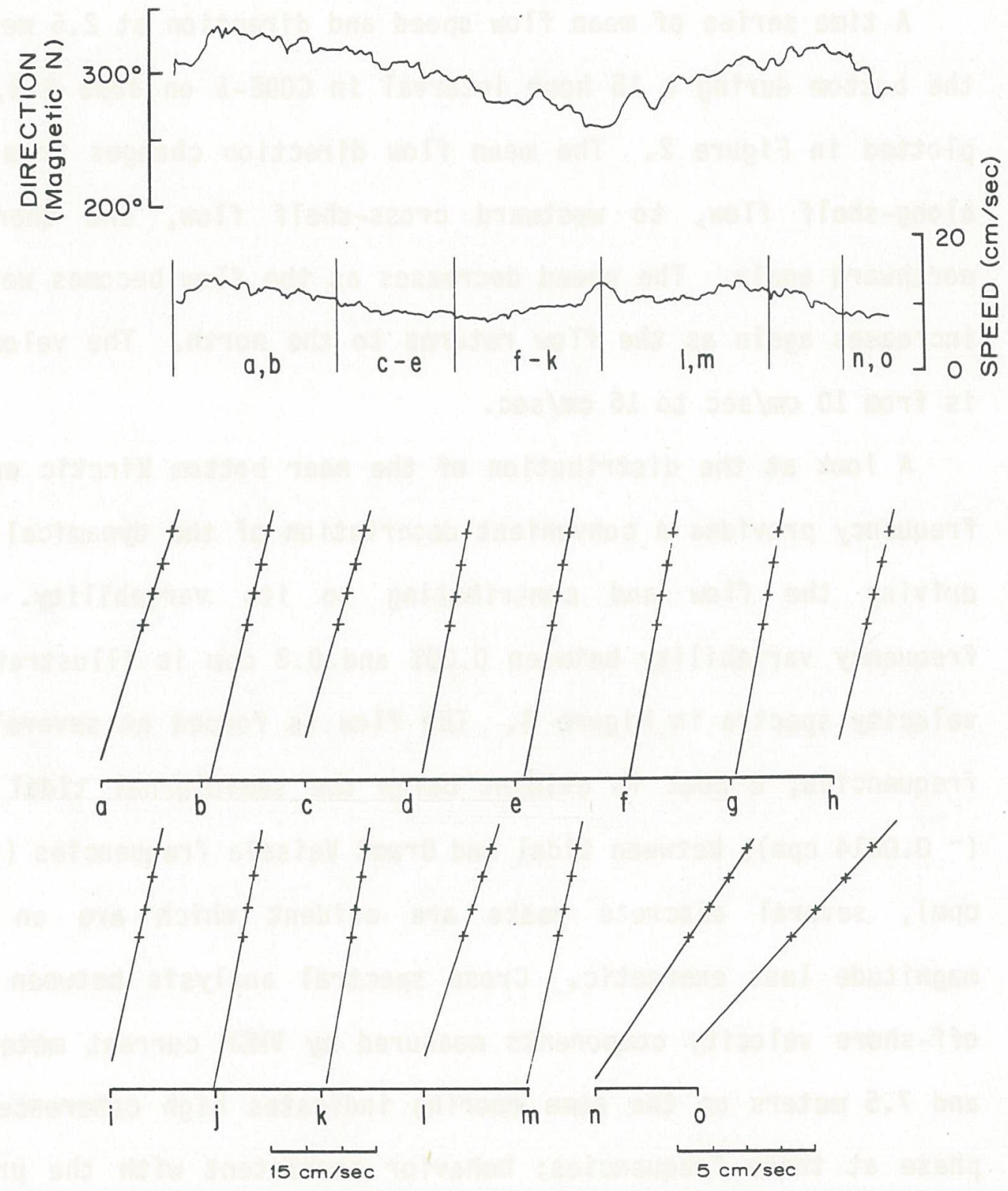

Figure 2: 15 hour record of near bottom flow at $21 / 2$ meters above the bottom at C3 (90 meters of water) during CODE-1 starting approximately $2000 \mathrm{hrs.} \mathrm{on} \mathrm{June} 2$, 1981. The upper plot is direction and the lower plot is speed; both are $3.33 \mathrm{~min}$. averages of a NBIS acoustic current meter sampled at $1 \mathrm{~Hz}$. Along isobath northward flow is $317^{\circ}$. The profiles are plots of $\log z$ (vertical axis) vs. time averaged (9.33 min) velocity (horizontal axis). The velocity measurements made using the WHOI tripod system are indicated by (+) at 28, 53, 103, and 203 centimeters above the bottom. The straight lines represent the best fit linear regression line to the points. The approximate time locations of the selected profiles are indicated on the speed plot. (Note: Profiles $n$ and o correspond to a different velocity scale). 


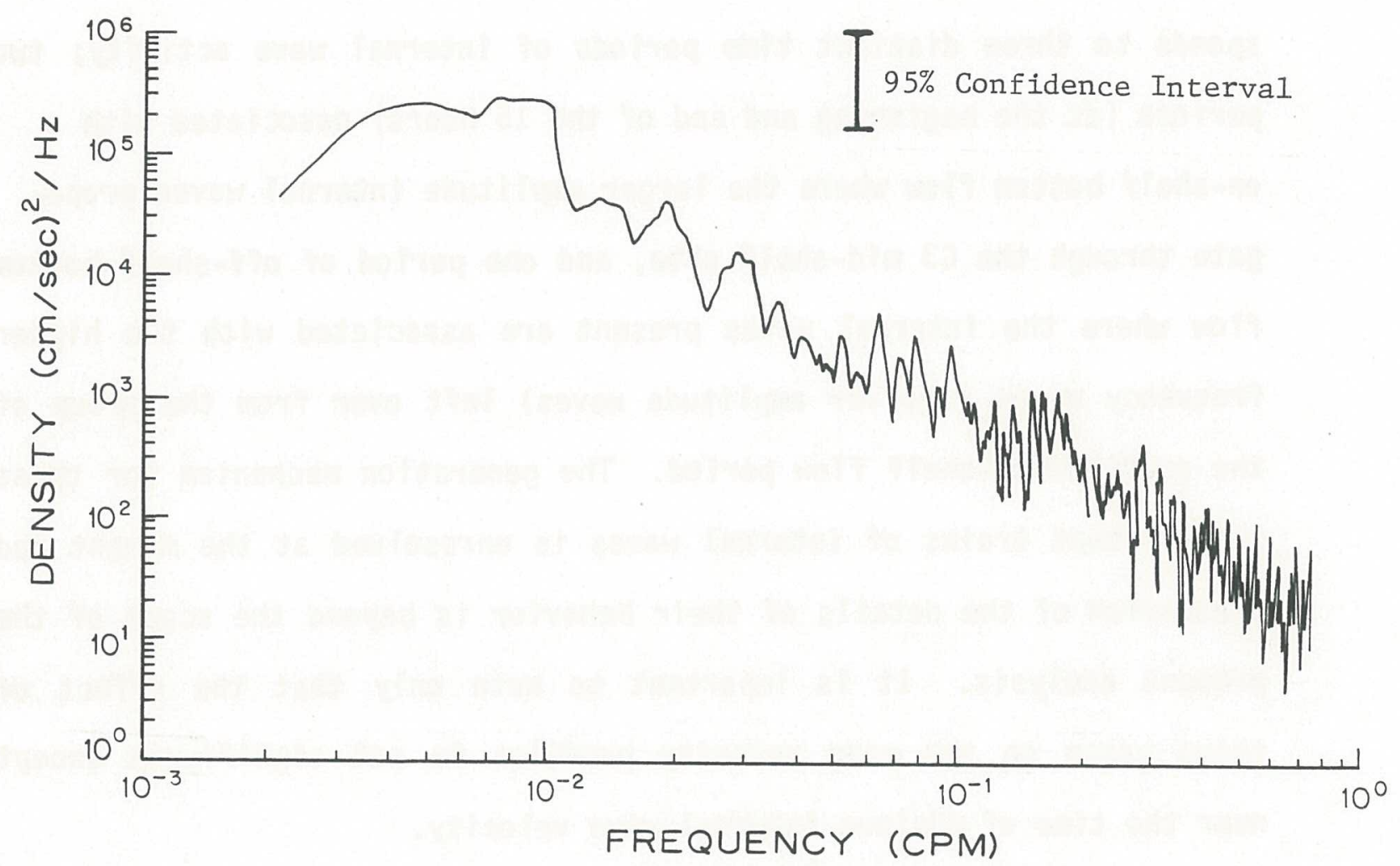

Figure 3: Horizontal velocity density spectra (10 degrees of freedom) from $21 / 2$ meters above the bottom for a 32 hour time period including 15 hours shown in Figure 1. The frequency scale extends from tidal to just below surface waves. 
in individual groups and are intermittently present. Typically, the groups consist of one long period (4-5 hours), large amplitude wave with smaller amplitude, shorter period (1-2 hours) waves following. The time period covered by the 15 hour velocity record actually corresponds to three distinct time periods of internal wave activity; two periods (at the beginning and end of the 15 hours) associated with on-shelf bottom flow where the larger amplitude internal waves propagate through the $\mathrm{C} 3 \mathrm{mid}-\mathrm{shelf}$ site, and one period of off-shelf bottom flow where the internal waves present are associated with the higher frequency waves (smaller amplitude waves) left over from the group of the previous on-shelf flow period. The generation mechanism for these intermittent trains of internal waves is unresolved at the moment and discussion of the details of their behavior is beyond the scope of the present analysis. It is important to note only that the effect of these waves on the mean velocity profiles is not significant except near the time of maximum internal wave velocity.

The effect of the internal waves on the velocity profiles is primarily kinematical resulting from unsteady effects associated with taking time averages over portions of the internal wave cycle. The energy associated with the peak internal wave velocities reaching the bottom is one to two orders of magnitude smaller than the energy from tidal or surface wave velocities. As a result, the maximum shear stresses from the waves are much smaller than the mean stress and the time-averaged stress contribution from the internal waves is generally insignificant (Grant, 1982). Thus, although mean velocity profiles are sometimes effected, mean stress profiles are unchanged by the internal 
waves. The intermittent presence of these waves is helpful in examining their effect on the mean flow velocity profiles since at times, no waves are present. Also, the higher frequency waves have relatively smaller amplitudes and their velocity attenuates more quickly with depth than the earlier arriving lower frequency waves. Thus, the higher frequency waves have less influence on the mean velocity profiles.

The most energetic component of high frequency variability in the near bottom flow is due to long surface waves (swe11). Estimates of wave direction made from velocity and pressure sensors show the swell to be propagating from a south-southwesterly direction. Figure 4 shows a typical spectral density for $1.2 \mathrm{cpm}(0.02 \mathrm{~Hz})$ and higher frequencies for a 20 minute period during the time covered by the spectra in Figure 3. The wave peak, at about 15 seconds, is narrow band and drops off to the spectral gap between the wave peak and the internal wave band. Comparison of wave spectra over several hours indicates that the 1 ong period swell present was not stationary over time periods 1onger than one to two hours; the peak frequency shifts between 14 to 18 seconds. Some beating is present in the swell arrival pattern at al1 times; a typical 10 minute pressure record plotted in Figure 5 (from the 20 minute time period of Figure 4), clearly illustrates the beating phenomena.

At frequencies above the surface wave band the velocity spectra falls off rapidly as illustrated in Figure 4. This trend is expected in the inertial subrange region of the turbulent kinetic energy spectrum for wave numbers greater than approximately $2 \pi / z_{1}$, where $z_{1}$ is the height the measurement is made at. The vertical turbulent kinetic 


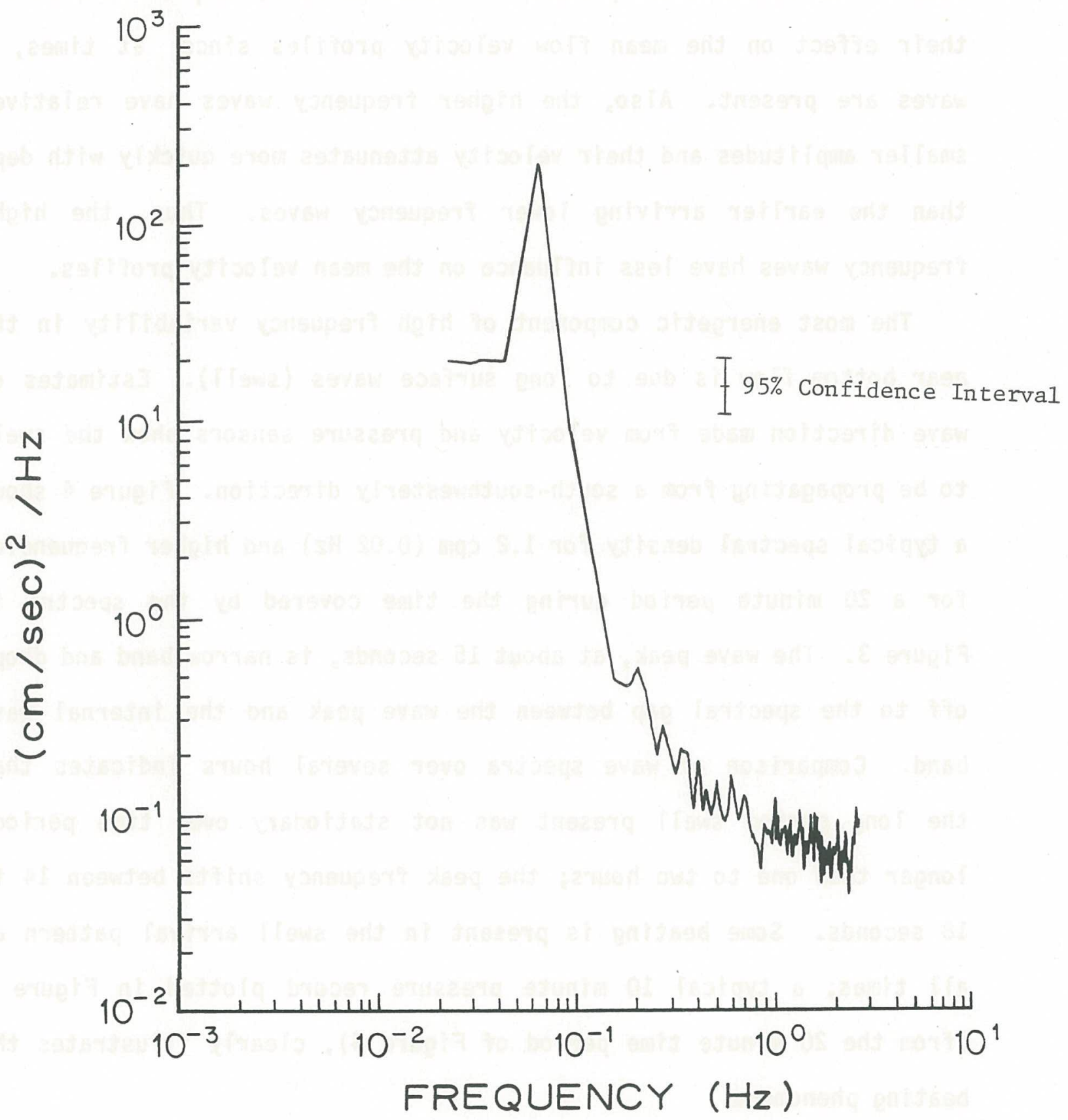

Figure 4: Horizontal velocity density spectra (54 degrees of freedom) showing surface wave band for a 20 minute period corresponding profiles d and e in Figure 2. Note aliasing is present at high frequency because of the sensor volume averaging. 


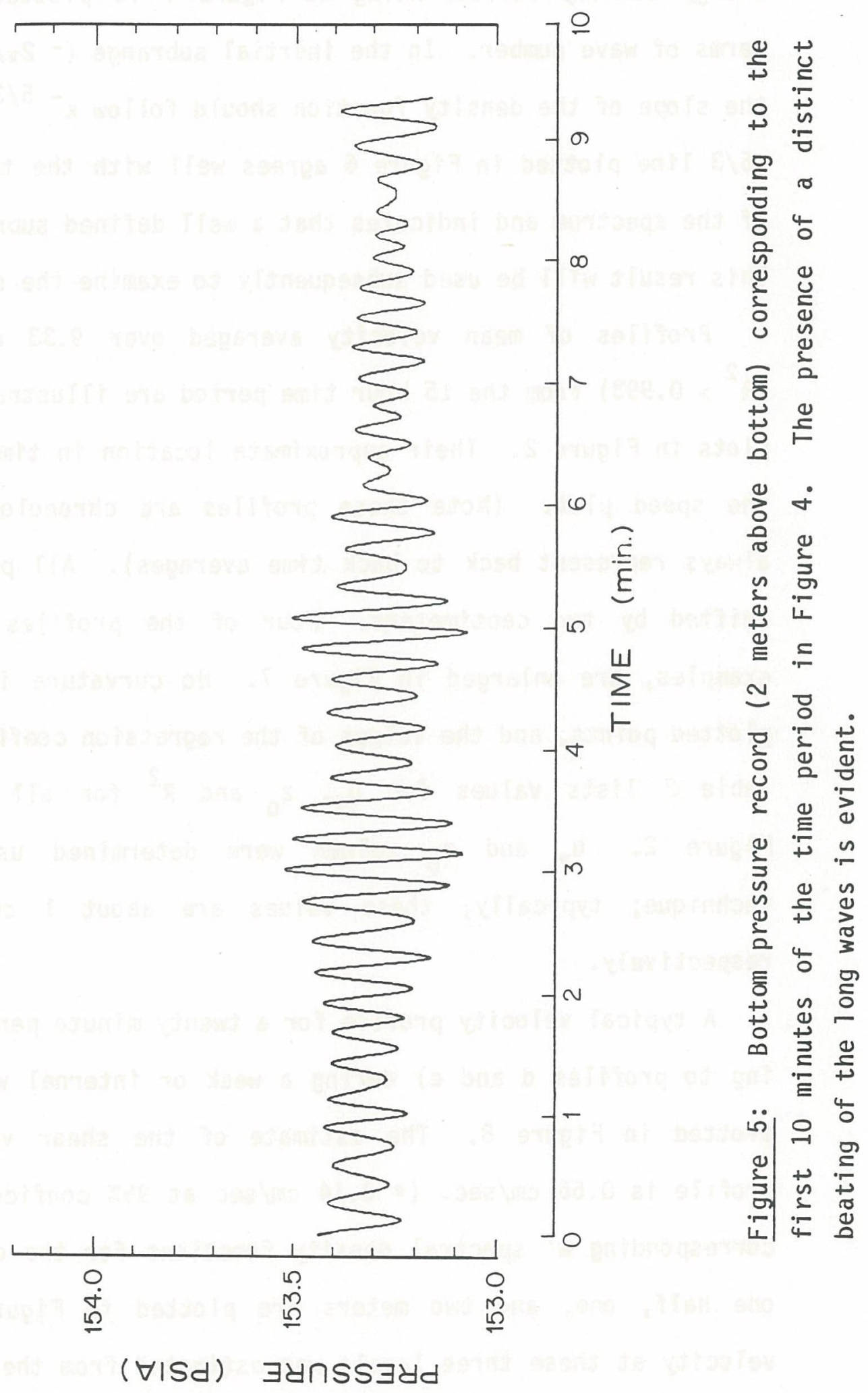


energy density corresponding to Figure 4 is plotted in Figure 6 in terms of wave number. In the inertial subrange $\left(\sim 2 \pi / z_{1}-2 \pi / 15 \mathrm{~cm}\right)$ the slope of the density function should follow $k^{-5 / 3}$ from (4). The $-5 / 3$ line plotted in Figure 6 agrees well with the trend in the slope of the spectrum and indicates that a well defined subrange does exist. This result will be used subsequently to examine the stress distribution.

Profiles of mean velocity averaged over 9.33 minutes, selected $\left(R^{2}>0.993\right)$ from the 15 hour time period are illustrated in semi-log plots in Figure 2. Their approximate location in time is indicated on the speed plot. (Note these profiles are chronological but do not always represent back to back time averages). All profiles were zero shifted by two centimeters. Four of the profiles used as typical examples, are enlarged in Figure 7. No curvature is evident in the plotted points, and the values of the regression coefficient are high. Table 2 lists values for $u_{*}, z_{0}$ and $R^{2}$ for all the profiles in Figure 2. $u_{*}$ and $z_{0}$ values were determined using the profile technique; typically, these values are about $1 \mathrm{~cm} / \mathrm{sec}$ and $1 \mathrm{~cm}$, respectively.

A typical velocity profile for a twenty minute period (corresponding to profiles $d$ and e) during a weak or internal wave free time is plotted in Figure 8. The estimate of the shear velocity from the profile is $0.56 \mathrm{~cm} / \mathrm{sec} .( \pm 0.14 \mathrm{~cm} / \mathrm{sec}$ at $95 \%$ confidence level). The corresponding $W^{\prime}$ spectral density functions for the current meters at one half, one, and two meters are plotted in Figure 9. The shear velocity at these three levels was estimated from the spectral density using (7) and found to be equal to $0.41,0.44$ and $0.48 \mathrm{~cm} / \mathrm{sec}$, 


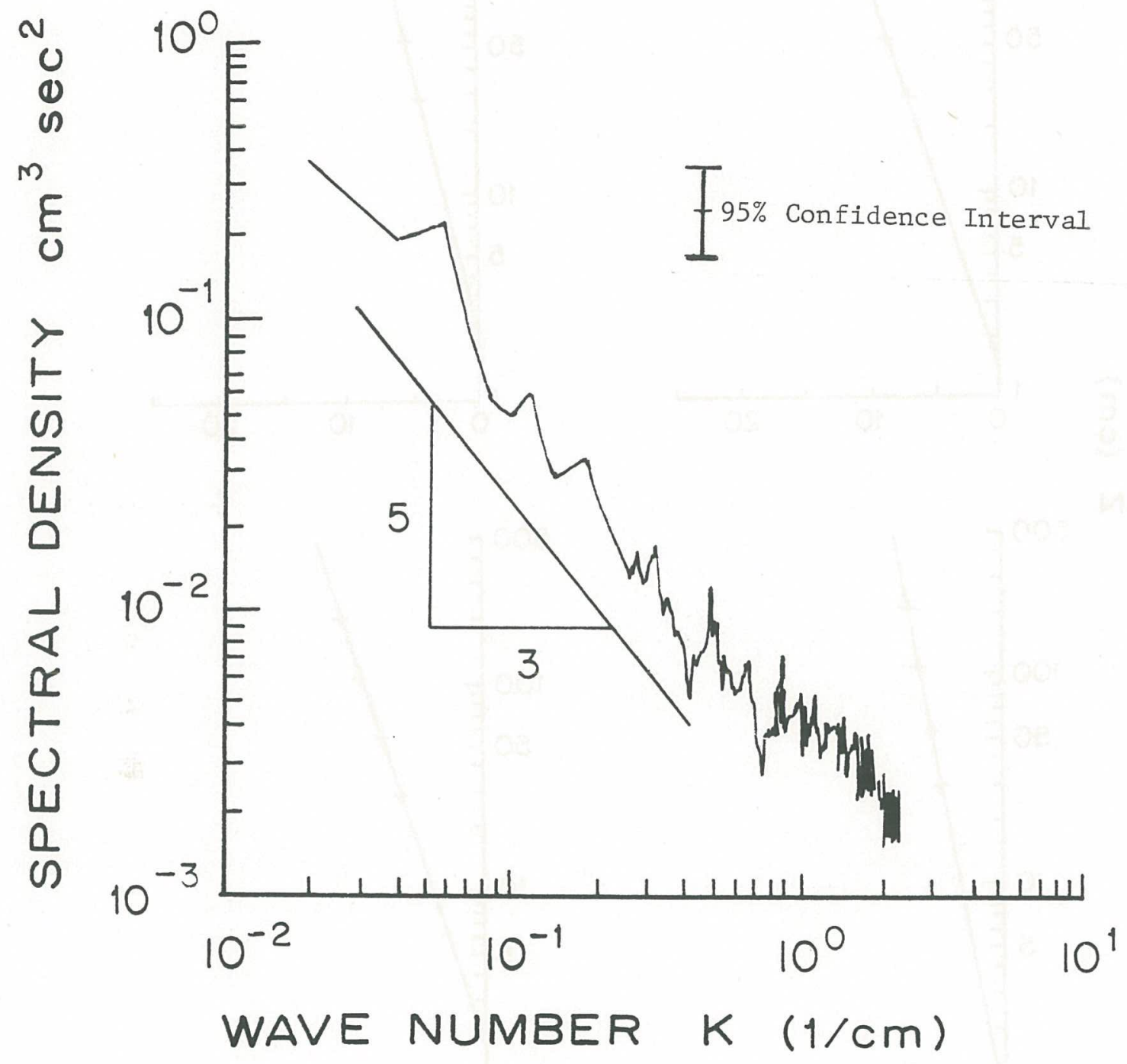

Figure 6: Vertical velocity density spectra ( $\left.w^{\prime}\right)$ (54 degrees of freedom) for frequencies from surface waves into the inertial subrange. The time period corresponds to Figure 4. The subrange spectra shows a distinct wave number dependency of $k^{-5 / 3}(k=2 \pi f / u$, where $u$ is the mean velocity). Note aliasing at high wave numbers corresponding to the cut off wave number for the sensor averaging volume. This demonstrates that the flow was over sampled. 

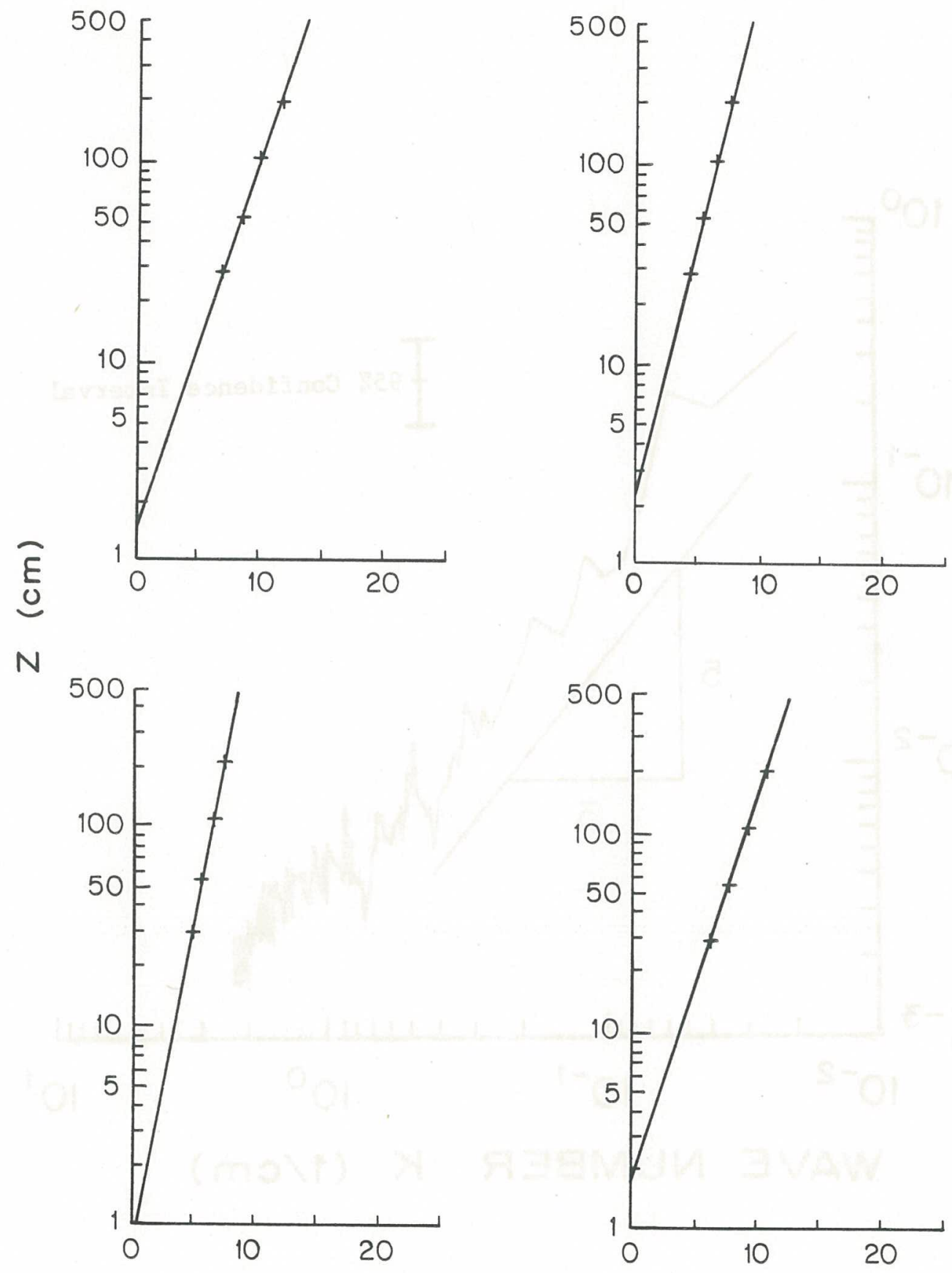

$U(\mathrm{~cm} / \mathrm{sec})$

Figure 7: Velocity profiles $a, h, j$ and 1 from Figure 2. The excellent agreement with log profiles is evident. Note, there is no consistent curvature in the profiles and the large $R^{2}$ values indicate small error bars on the $u_{*}$ and $z_{0}$ estimate made from these profiles. The corresponding values of $R^{2}, u_{*}$ and $z_{0}$ are given in Table 2 . 
ำำ

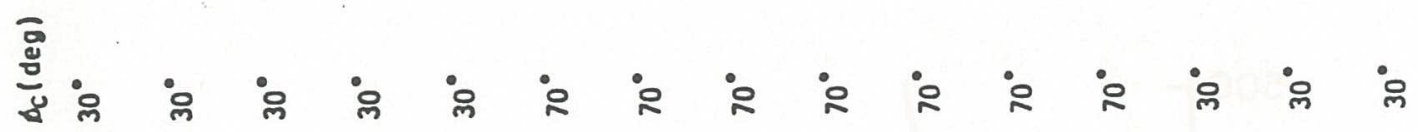

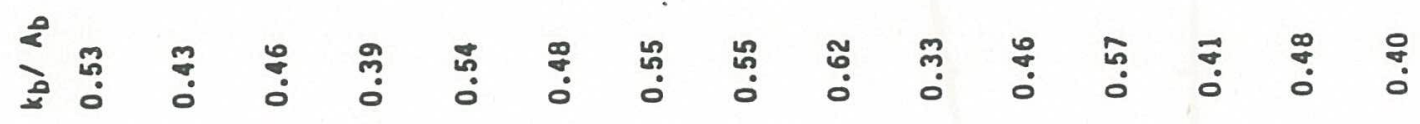

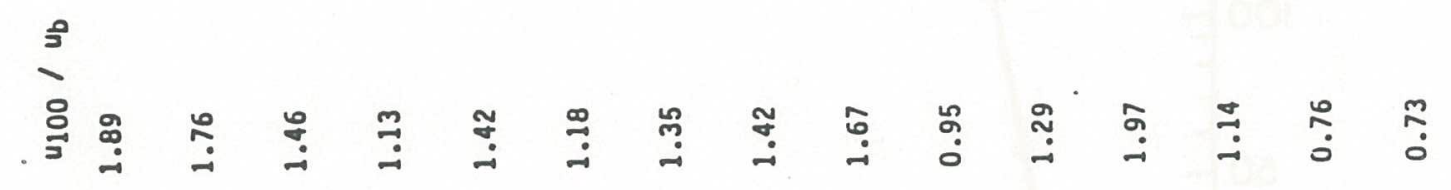

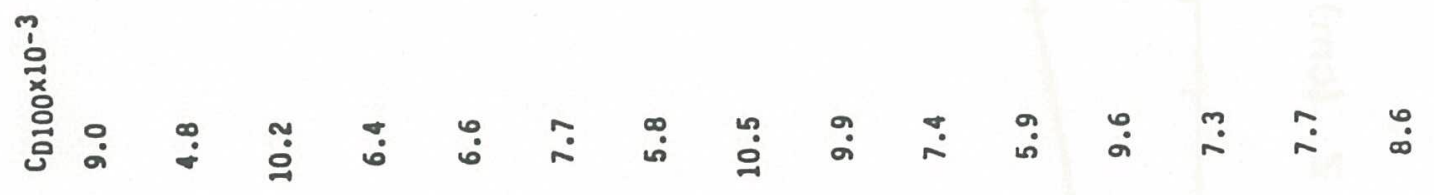

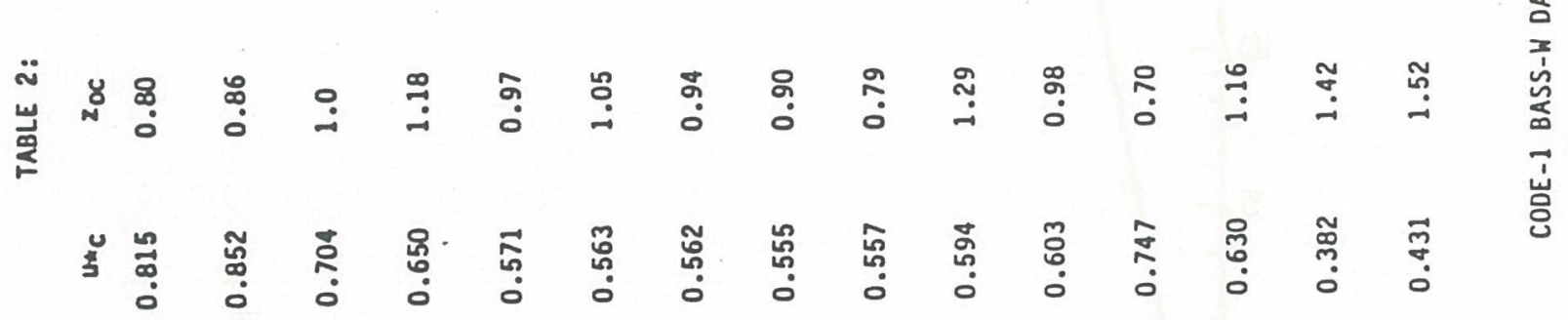

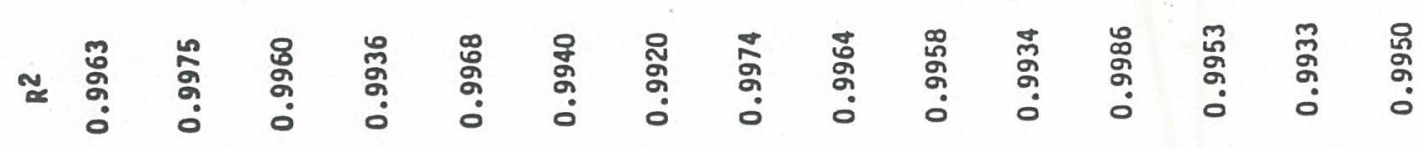

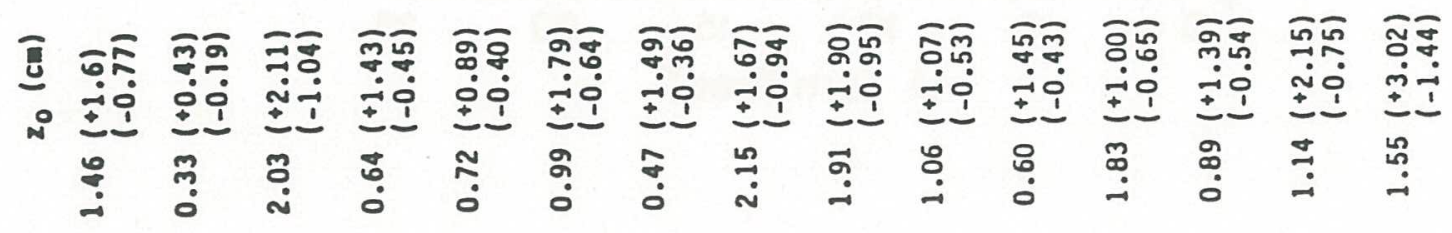

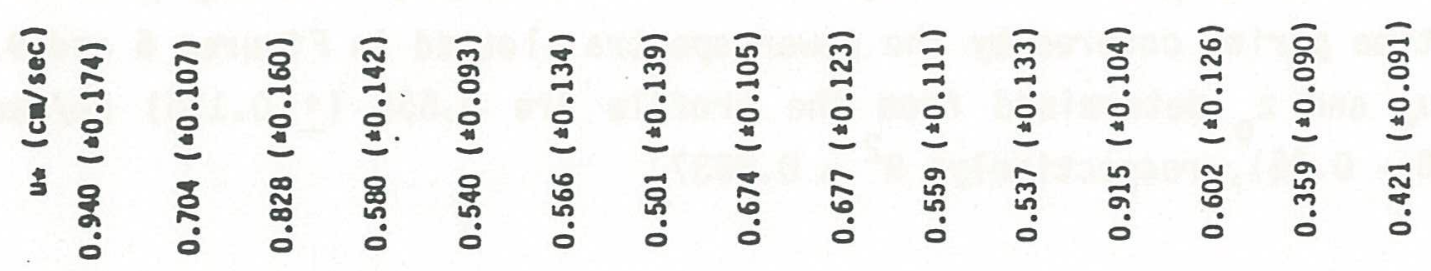

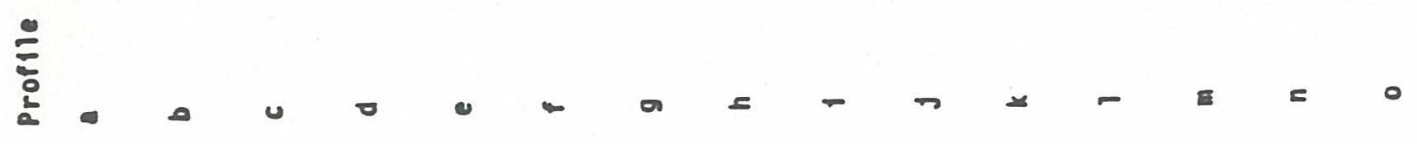




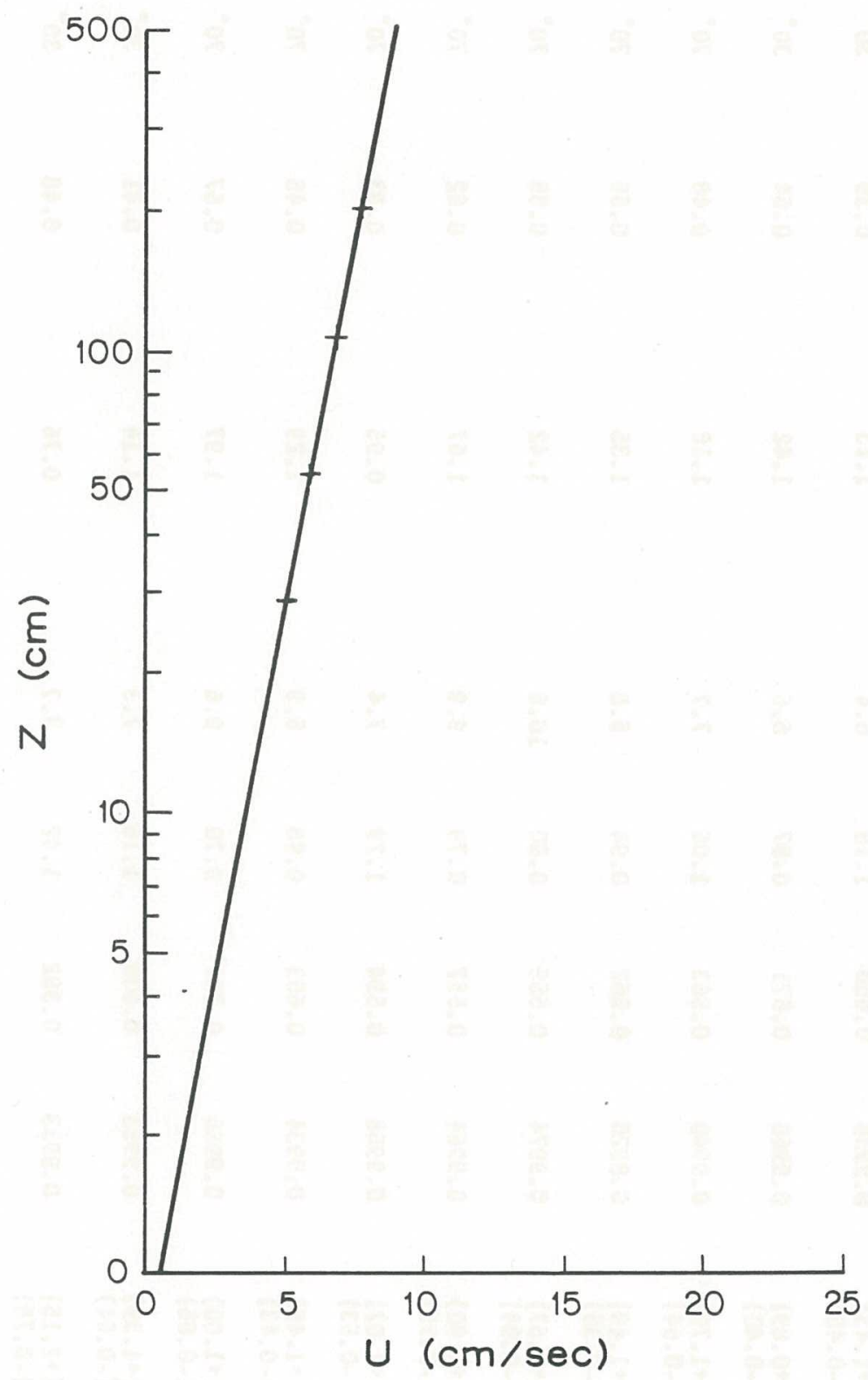

Figure 8: Mean velocity profile (averaged over 20.5 minutes, covering profile d and e) for the time period covered by the power spectra plotted in Figures 6 and 9. The values of $u_{\star}$ and $z_{0}$ determined from the profile are $0.556( \pm 0.135) \mathrm{cm} / \mathrm{sec}$. and $0.65(+1.48-0.45)$, respectively; $R^{2}=0.9937$. 


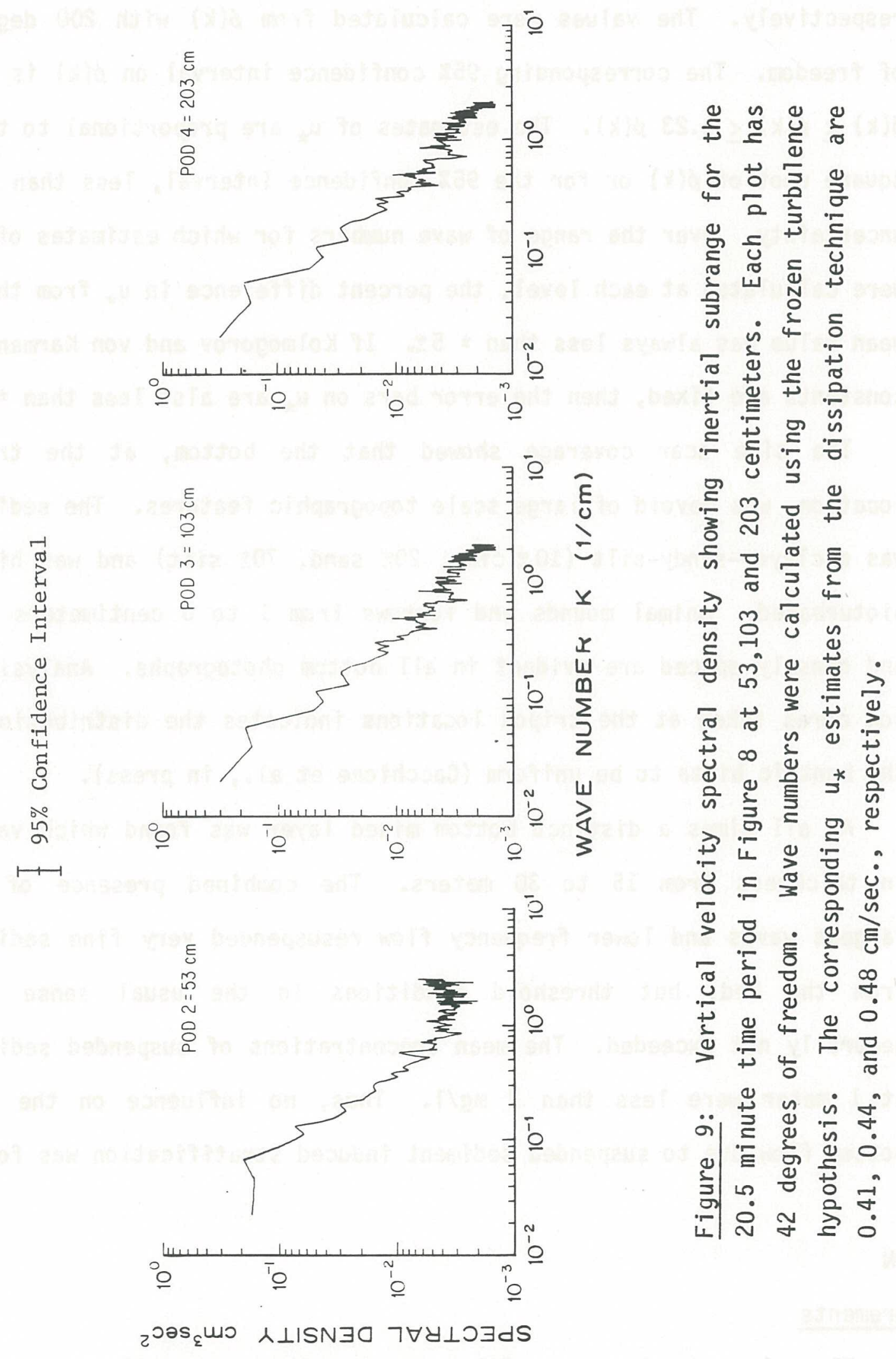


respectively. The values were calculated from $\phi(k)$ with 200 degrees of freedom. The corresponding $95 \%$ confidence interval on $\phi(k)$ is 0.83 $\phi(k) \leq \phi(k) \leq 1.23 \phi(k)$ : The estimates of $u_{*}$ are proportional to the square root of $\phi(k)$ or for the $95 \%$ confidence interval, 1 ess than a $5 \%$ uncertainty. Over the range of wave numbers for which estimates of $u_{\star}$ were calculated at each level, the percent difference in $u_{*}$ from the mean value was always less than $\pm 5 \%$. If Kolmogorov and von Karman constants are fixed, then the error bars on $u_{\star}$ are also less than $\pm 5 \%$.

The side scan coverage showed that the bottom, at the tripod location, was devoid of large scale topographic features. The sediment was a clayey-sandy-silt ( $10 \%$ clay, $20 \%$ sand, $70 \%$ silt) and was highly bioturbated. Animal mounds and furrows from 1 to 5 centimeters high and densely spaced are evident in all bottom photographs. Analysis of box cores taken at the tripod locations indicates the distribution of the benthic biota to be uniform (Cacchione et al., in press).

At all times a distinct bottom mixed layer was found which varied in thickness from 15 to 30 meters. The combined presence of the largest waves and 1 ower frequency flow resuspended very fine sediment from the bed, but threshold conditions in the usual sense were generally not exceeded. The mean concentrations of suspended sediment at 1 meter were less than $2 \mathrm{mg} / 1$. Thus, no influence on the near bottom flow due to suspended sediment induced stratification was found.

\section{DISCUSSION}

\section{a. Measurements}

The selected velocity profiles are described accurately by a logarithmic velocity distribution as evidenced by $R^{2}$ values greater than 
0.993 and no systematic deviation of the measured points from the best fit line. This latter observation is consistent with the support data which indicates that during the times picked, stratification, internal waves and topographic features are negligible at the site. The existence of a pronounced inertial subrange in the velocity spectrum is also consistent with the observed logarithmic behavior of the velocity profiles.

The precision of the measurements of the height of the velocity sensors above the seabed is better than one centimeter with the mechanical system and on the order of a millimeter with the acoustic system. In spite of this high precision, the use of the measurement is not simple. The height of the sensor above the average bottom around the tripod is needed. The height measurement is made at a point and is therefore affected by local micro-topography, i.e., biologically induced mounds, indentations and/or slight undulations in the bottom. An estimate of the uncertainty in the bottom location is about 5 centimeters; zero shifts within this range of uncertainty in the velocity profiles were found to have a minor effect on the estimates of $z_{0}$ and $u_{\star}$ based on the velocity profiles. Pitch and roll measurements indicated no tripod settlement occurred during the analysis period. Estimates of the displacement thickness, using the results of Jackson (1981), are on the order of one centimeter. These estimates are within the uncertainty of the bottom location; thus correcting the profiles for the displacement thickness has negligible effect on the profiles. Therefore, the final selection of sensor height above the bottom (within the $5 \mathrm{~cm}$ uncertainty) was picked by maximizing the regression 
fit of a logarithmic profile to the actual measured velocity points (a $2 \mathrm{~cm}$ shift was used).

Averaging time intervals between 9 and 14 minutes consistently gave the highest $R$ values. Other averaging intervals of 4.67 and 18.67 minutes yielded very similar results for $u_{*}$, but in general, increased the scatter in $z_{0}$ and decreased the regression coefficients slightly. Averaging times less than 4.67 minutes significantly 1 owered the regression coefficients and increased the scatter in both $u_{\star}$ and $z_{0}$.

It is well established that the existence of logarithmic profiles requires averaging the instantaneous velocity for 1 ong enough to properly average the eddy structure in the flow (Townsend, 1970). The short term averages require that the time must be sufficiently greater than the eddy mixing time scale $z / u_{\star}$. For the CODE site in the lower two meters this is at least four or five minutes $\left(z / u_{*} \sim 0\left(10^{2}\right) \mathrm{sec}\right)$. However, the beat period of the surface waves is on the order of two minutes and averages over several periods are needed. This means a minimum averaging time of close to 10 minutes is desirable. Thus, some degradation of the velocity profiles at lower averaging times is expected. As the averaging interval is increased, effects of nonstationarity and unsteadiness in the flow field become important. The variability in the bottom velocity profiles due to the intermittent internal waves with frequencies of $10^{-2} \mathrm{cpm}$ and 1 ower, although weak, could still be picked out. Averaging intervals must be kept small, relative to internal wave variability and this generally limited averages to 30 minutes or 1ess. It was not possible to average over longer times to remove internal wave effects because the system is 
not stationary at these longer time scales as evidenced by the swell behavior and the variability in the bottom currents (Figure 2). The choice of an averaging interval of approximately 10 minutes, maximized the regression coefficient in most cases.

The net result from the choice of zero shifts and averaging times is to maximize the value of the regression coefficients for the profiles and minimize the error bars on the estimates of $u_{\star}, z_{0}$ and the velocity profiles. The 95 percent confidence intervals on the estimates are included in Table 2. The values on $u_{*}$ are always less than 25 percent and as 1 ow as 10 percent. One of the goals in the short-term experiment was to test a model to predict the bottom stress at the site. In order to simplify the comparison between stress and $z_{0}$ estimates from data and theory, we wished to avoid the complications involved with correcting velocity profiles for kinematical effects associated with internal waves. The choice of the large regression coefficients assures valid comparisons.

The shear velocity estimates based on the velocity profile technique and the inertial dissipation technique (Figures 8 and 9) agree within statistical limits. Furthermore, the shear velocity estimates at all three meters show very close agreement. The picture is consistent with a constant stress layer and the corresponding existence of a logarithmic velocity profile. The large $u_{*}$ and $z_{0}$ values corresponding to this example are typical of the other estimates based on the profile analysis.

The results of this agreement indicate that velocity profiles can be used to estimate stress with very specific limitations. The first 
limitation is that the fit of the velocity profile to a logarithmic distribution must be sufficiently good (as measured by the regression coefficient and curvature in the profile). that the stress is within some preset error bars. The error bars are set by the confidence level desired, and the current meter configuration (1ocation and number). A simple expression for the confidence bands (Gross and Nowe11, in press) is

$$
\hat{u}_{\star}(1-e) \leq \hat{u}_{\star} \leq \hat{u}_{\star}(1+e)
$$

where $u_{*}$ is the estimate of $u_{*}$ and $e$ is given by

$$
e=\left(t_{\alpha / 2}, n-2\right)\left[\frac{1}{n-2}\left(\frac{1-R^{2}}{R^{2}}\right)\right]^{1 / 2}
$$

where $t$ is the student's $t$ distribution for the $(1-\alpha)$ confidence interval with $n-2$ degrees of freedom, $n$ is the number of current meters and $R$ is the regression coefficient (or sample correlation coefficient). For a 95 percent confidence interval with four current meters at 30 , 55, 105 and 205 centimeters, $R^{2}$ equal to 0.993 corresponds to a 25 percent variation in $u_{*}$. For the same configuration $R^{2}=0.9$ corresponds to 100 percent variation in $u_{*}$.

The second limitation is the averaging time as discussed above. Spectra by themselves do not resolve the problem sufficiently and a careful analysis of the time series of events is important. The third major limitation is the knowledge of the bed origin. It is important to have some method to set limits on zero shifts in the velocity profiles. Even a bottom locator at a single point must be interpreted with care. 
The profiles exhibit large values of $z_{0}$ and $u_{*}$ relative to those typically expected for steady uniform flow. For the velocities observed at 1 meter, the corresponding drag coefficients, $C_{D}$, range from $4 \times 10^{-3}$ to $10 \times 10^{-3}$ (based on ${ }_{C}={ }_{C} C_{D}|u| u$ ). These values are approximately 3 to 6 times larger than the $1.5 \times 10^{-3}$ that most modelers use for the shelf. The range of $z_{0}$ values of 0.3 to 1.9 centimeters is large for the bioturbated bottom carefully observed in bottom photographs and box core surfaces; an estimate of the physical $z_{0}$ for these features is about $10^{-1}$ centimeters; nearly an order of magnitude smaller than estimated from the majority of the profiles (Table 2).

Control in the experiment is good and the support data justifies the neglect of effects associated with internal waves, stratification and large scale upstream topography. The type of behavior observed in the mean flow profiles is qualitatively expected based on the combined wave and current models developed by Grant and Madsen (1979) and Smith (1977). The measurements of velocity were made outside the wave boundary layer region where enhancement of the mean stress and apparent roughness are predicted to occur. (Estimates of boundary layer thickness are made below to show that this is the case). We demonstrate in the next section that interaction between the low frequency currents and surface waves provide a dynamical explanation for the observed profile behavior.

b. Comparison with Combined Wave and Current Models

1. Theoretical model: The physical situation treated by the combined wave and current models is described in Grant and Madsen (1979) and 
briefly summarized here. As derived below, unsteady boundary layers have thicknesses which scale as $\kappa u_{\star} / \sigma$ where $u_{*}$ and $\sigma$ are the characteristic shear velocities and frequencies, respectively: Thus, because of the contrasting time scales associated with the combined wave and current flow, two distinct bottom boundary layer regions develop. A wave boundary layer develops in the immediate vicinity of the boundary, its growth being limited by its short time scale to several centimeters for the flow characteristics in the experiments. The wave boundary layer is nested within a thicker current boundary layer whose thickness is 1 imited by the 1 ocal inertial frequency. This current boundary layer develops well away from the boundary up to 20 to 40 meters in height for the flow conditions at CODE. Within the wave boundary layer, the turbulence intensities are due to the combined flow which is coupled in a non-linear manner. Above the wave boundary layer (i.e., in the potential flow region for the wave), the turbulence is associated only with the low frequency "mean" flow. This mean flow is altered, however, because of the flow momentum removed below by the action of the combined shear flow. The result is that the current above the wave boundary layer experiences a shear stress dependent on the wave boundary layer characteristics as well as on the physical boundary characteristics, i.e., animal mounds, ripples, etc.

Mathematically, we describe the near bottom fluid motion in both regions, neglecting non-linear and Coriolis terms, as

$$
\frac{\overrightarrow{\partial u}}{\partial t}=-\frac{1}{\rho} \vec{\nabla}_{H} \quad p+\frac{\partial}{\partial z}\left(\frac{\vec{\tau}}{\rho}\right)
$$


where $\tau$ is the bottom stress, $t$ is the time, $\vec{\nabla}_{H}$ is the horizontal vector operator

$$
\vec{\nabla}_{H}=\frac{\partial}{\partial x} \vec{i}+\frac{\partial}{\partial y} \vec{j}
$$

$p$ is the pressure

$$
p=p_{W}+p_{C}
$$

and $u$ is the velocity vector

$$
\vec{u}=\vec{u}_{w}+\vec{u}_{c}
$$

where the subscripts $w$ and $c$ indicate the components due to the wave and current, respectively.

In the Grant and Madsen (1979) model, turbulence closure for (11) is made through a linearly varying eddy viscosity given by

$$
v_{T}=\kappa \quad u_{\star} z
$$

where $u_{*}$ is the characteristic shear velocity for the flow. Equation (15) is a useful approximation to the full eddy viscosity profile given approximately by $k u_{*} z e^{-z / h}$ where $h$ is the boundary layer scale height (e.g., Long, 1981; Glenn, 1983; Grant and Glenn, 1983) and permits analytic solutions to be found to (11).

Since two distinct boundary layers exist for the flow, a characteristic shear velocity for each region must be determined. These shear velocities are found using the definition of the instantaneous boundary shear stress

$$
\vec{\tau}_{b}=\frac{1}{2} \text { of }{ }_{c w}\left(u^{2}+v^{2}\right)\left[\frac{u}{\left(u^{2}+v^{2}\right)} 1 / 2, \quad \frac{v}{\left(u^{2}+v^{2}\right)} 1 / 2\right]
$$


where $f_{C W}$ is a wave-current friction factor, and $u$ and $v$ are the $x$ and $y$ components of the instantaneous horizontal velocity. Adopting the convention that the $x$ axis is always in the direction of wave propogation, $u$ and $v$ are

$$
\begin{aligned}
u= & \left(\sin \theta+\frac{\vec{u}_{a} \mid}{\left|\vec{u}_{b}\right|} \cos \phi_{c}\right)\left|\vec{u}_{b}\right| \\
v= & \left(\frac{\overrightarrow{u_{a}} \mid}{\mid \overrightarrow{u_{b}}}\right) \sin \phi_{c}\left|\vec{u}_{b}\right|
\end{aligned}
$$

where $\left|\vec{u}_{a}\right|$ is the magnitude of the steady current velocity at a height, $a$, above the bed, $b_{c}$ is the angle made by $\left|\vec{u}_{a}\right|$ with the direction of wave propagation, $\left|\vec{u}_{b}\right|$ is the maximum near bottom orbital wave velocity from linear wave theory

$$
\left|\vec{u}_{b}\right|=\frac{H}{2 \sinh k h} \omega
$$

in which $H$ is the wave height, $k$ is the wave number, $h$ is the water depth and $w$ is the radian wave frequency.

In the region above the wave boundary layer, i.e., the potential flow region for the wave, the stress is associated with only the mean flow and the current above feels the time-averaged stress. The instantaneous flow is continually changing direction, and (16) is time averaged with respect to direction to define the mean shear velocity in the outer region, $\left|\vec{u}_{*_{c}}\right|$. Inside the wave boundary layer the majority of turbulence production occurs during the maximum wave velocity and the characteristic shear stress for this region is argued to be the maximum, 


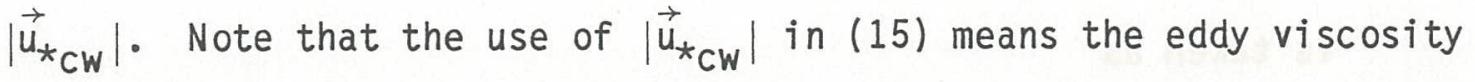
is time independent. In addition to the physical reasons stated, Trowbridge (personnel communication) has demonstrated that to first order the time variation may be neglected in a fully time dependent eddy viscosity model.

The respective wave and current velocity profiles are found by solving (11) in each boundary layer region using the proper shear velocity for each region as defined above. From the governing equation for the wave motion within the wave boundary layer it is easily shown that the vertical scale of the oscillatory boundary layer is

$$
l=\frac{\kappa\left|\vec{u}_{\star_{C w}}\right|}{\omega}
$$

The primary interest here is in solutions for the mean flow in each boundary layer region. To solve for the steady component of (11), the usual boundary layer assumption is applied and a constant stress region is assumed to exist in each layer. Within the wave boundary layer the usual no-slip boundary condition is

$$
\vec{u}=0 \quad \text { at } \quad z=z_{0}
$$

where $z_{0}$ is the physical bottom roughness length; that is, the roughness scale associated with bedforms, ripples, or animal mounds, for example. The resulting velocity profile in this region (Grant and Madsen, 1979) is

$$
|\vec{u}|=\frac{\left|\overrightarrow{u_{\star_{C}}}\right|}{\kappa} \frac{\vec{u}_{\star_{C}} \mid}{\left|\overrightarrow{u_{\star_{C} w}}\right|} \ln \frac{z}{z_{0}} \quad z<\delta_{w}
$$

For the flow above the wave boundary layer the no-slip condition 
is taken as

$$
\vec{u}=0 \text { at } z=z_{\text {oc }}
$$

where $z_{o c}$ is the apparent roughness which reflects the influence of both the physical bottom roughness and the dissipation associated with the wave generated turbulence.

Using the condition in (23) the solution for the mean flow above the wave boundary layer is

$$
\vec{u} \mid=\frac{\left|u_{* c}\right|}{k} \ln \frac{z}{z_{\text {oc }}} \quad z>\delta_{w}
$$

The relation between the two roughness lengths $z_{0}$ and $z_{0 C}$ is determined by matching the velocity profiles across the boundary layer interface. Equating (22) and (24) at $\mathrm{z}=2$ l (equation 20), the ratio between the apparent roughness and physical bottom roughness is

$$
\begin{aligned}
& \frac{z_{o c}}{z_{0}}=24\left[\frac{\left|\vec{u}_{\star_{C W}}\right|}{\left|\vec{u}_{b}\right|} \frac{\vec{A}_{b} \mid}{k_{b}}\right]^{B} \\
& B=\left(1-\frac{\left|\vec{u}_{\star_{C}}\right|}{\left|\vec{u}_{b}\right|} \frac{\left|\vec{u}_{b}\right|}{\left|\vec{u}_{\star_{c W}}\right|}\right)
\end{aligned}
$$

where $k_{b}$ is the equivalent roughness height equal to $30 z_{0}$ for rough turbulent flow.

Grant and Madsen (1979) define the wave boundary layer thickness as $\delta_{w}=2 l$, where $l$ is given by (20). With this definition and noting $\left|\vec{u}_{b}\right|=\left|\vec{A}_{b}\right| \omega$, (25) can be rewritten for rough turbulent flow as 


$$
\frac{z_{O C}}{z_{0}}=24^{1-\beta}\left(\frac{\delta}{z_{0}}\right)^{\beta}
$$

Thus, (27) illustrates that the apparent roughness depends on the turbulent intensity within the wave boundary layer and the wave boundary layer thickness as well as the physical bottom roughness.

To apply the model summarized above, the wave friction factor and the apparent roughness must be determined. These are solved for in the model as a function of four parameters characterizing the near bottom flow. In dimensionless form these four parameters are (Grant and Madsen, 1979)

$$
\frac{z_{r}}{k_{b}}, \frac{\vec{u}_{c r} \mid}{\left|\overrightarrow{u_{b}}\right|}, \frac{k_{b}}{|\vec{A}|}, \delta_{c}
$$

where $\left|\vec{u}_{c r}\right|$ is the magnitude of the mean velocity at a height $z_{r}$ above the bed, $\bar{\phi}_{c}$ is the angle between the wave and current and $\left|\vec{u}_{b}\right|$ and $\left|\vec{A}_{b}\right|$ characterize the wave; and $k_{b}$ is the physical bottom roughness $\left(k_{b}=30 z_{0}\right)$. The iterative procedure used to calculate the stress, apparent roughness and velocity profile is described in Grant and Madsen (1979). (Note, if sediment transport is occurring, $z_{0}$ is a function of the shear stress and must be calculated iteratively as described in Grant and Madsen (1982) or Grant and Glenn (1983)).

2. Comparison with CODE-1 results: The CODE data set contains all the necessary information to calculate the four parameters in (28). For the conditions observed during the experiments, the wave boundary layer is 1 to 4 centimeters thick and is well below the measurement region of 
the 1 owest current meter located at approximately $30 \mathrm{~cm}$ above the bottom. Thus, according to the model the velocity profiles measured in CODE-1 correspond to the solution given by (24); the calculated roughness lengths correspond to the apparent roughnesses, $z_{O C}$, and the calculated shear velocities, $\vec{u}_{*_{c}} \mid$, correspond to the mean shear stress enhanced by the presence of the waves.

At the C3 station, bottom photographs and box cores show that the bed features are mounds and furrows created by benthic biota; they range in height from-1-5 centimeters and are spaced on the order of 10-30 centimeters apart (Cacchione et a1., in prep.). The height to width dimensions are nearly one to one. The available information on estimating roughness lengths for $3-D$ distributed roughness elements is sparse and even for uniformly distributed roughness elements the empirical approaches are based on only limited data. We based our estimates on the approach of Wooding et a1. (1973) where the roughness length $k_{b}$ is proportional to the roughness element height, $k$, its concentration, $\lambda$, and a 3-dimensional factor, $\phi$. Thus,

$$
k_{b} \propto k \lambda \propto
$$

where $\lambda$ is the ratio of the frontal area to the average area of the flat surface occupied by the roughness element, and 6 is proportional to the ratio of the height of the roughness element to its width, raised to an empirically determined power.

Grant and Madsen (1982) have demonstrated that (29) holds well for ripples in oscillatory flow with to taken as one and the proportionality constant between $k_{b}$ and $\lambda$ equal to approximately 30 . Most recently, 
Paola (1983) has carried out steady flow laboratory experiments over uniformly placed hemispheres corresponding to the concentration dependent roughness range where (29) should be valid. Experiments were also run with downstream tails on the hemisphere to investigate threedimensional flow effects. In all cases Paola found that $k_{b}$ was scaled best by a $k \lambda$ distribution.

Based on the seabed geometry and (29), an order of magnitude estimate for $k_{b}$ at the site is $30 k^{2} / L$, where $L$ is the spacing of the mounds. Plugging in typical numbers gives $z_{0}=k_{b} / 30=0\left(10^{-1}\right)$ centimeters. The flow conditions during the experiments were not sufficient to cause much sediment transport at the bed. Thus, the major contribution to the roughness should be expected to be from the animal mounds. Moreover, this roughness should stay constant during the course of the measurements because of the minimal amount of sediment transport.

Characteristic wave velocities and periods were determined from the data for input into the model through the parameters, $\left|\vec{u}_{c r}\right| /\left|\vec{u}_{b}\right|$ and $k_{b} /\left|\vec{A}_{b}\right|$, in (28). The mean flow was determined from averages over time periods of approximately 10 minutes. During any 10 minute time period there is variability in the surface waves as is obvious from the beating in Figure 5. The largest contribution to the wave induced turbulence during the time period the current is averaged over will be associated with the largest waves. The enhancement of the mean stress associated with the effect of surface waves is a highly non-linear process also weighted toward the largest waves. In addition, the apparent roughness is proportional to the total stress and the thickness of the wave boundary layer as seen from (27). 
Two possible choices for the wave description are then the maximum wave characteristics or the significant wave characteristics. Examination of the wave patterns, such as the one plotted in Figure 5, indicate that the envelope describing the waves are generally quite flat and the maximum and significant wave heights are not greatly different. The period also shows relatively little scatter. Thus, as a convenient choice in this data set, we characterize the waves by the amplitude of the envelope of the wave record over the mean flow averaging period and use the average wave period during this time.

To estimate the variability in the results of the model run due to the choice of statistics to represent the wave, we undertook a wave by wave analysis of several time series. The mean current over a given 10 minute interval was held constant. From the pressure record, the wave velocity and period were calculated for each individual wave over the same ten minute period. The model then was run for each wave and $\left|\vec{u}_{*_{C}}\right|$ and $z_{\text {oc }}$ were determined for the average of the individual runs. Comparison of this wave by wave result with the result using the beat envelope amplitude and average period showed only a 10 to 12 percent difference in $\left|\vec{u}_{*_{C}}\right|$ estimates and a 20 to 40 percent difference in $z_{o c}$. These numbers are well within the error bars on the respective estimates made from the velocity profiles; thus, the choice of the more easily calculated statistics is used here.

The combined wave and current model was run for the CODE data using as inputs the mean velocity at one meter, the wave velocity based on the maximum envelope amplitude and the average wave period over the time corresponding to the current averaging interval, the average 
direction between the wave and the current and an estimated value for the physical bottom roughness of $0.1 \mathrm{~cm}$. The value of the physical bottom roughness was then adjusted in increments of $0.1 \mathrm{~cm}$ until a good fit between the model predictions of $\left|\vec{u}_{\star_{c}}\right|$ and estimates from the data were obtained for the first two profiles. We found that the predictions of $\left|\vec{u}_{*_{c}}\right|$ were not highly dependent on the roughness estimates; a correction of 0.1 typically changed the percent difference between predicted and estimated values by no more than 12-15 percent. A value of $z_{0}$ equal to $0.2 \mathrm{~cm}$ ( or $k_{b}=6 \mathrm{~cm}$ ) was picked and held constant throughout the entire 15 hour period shown in Figure 2. This value is consistent with the estimates of the magnitude of roughness given above since the result given by (29) only provides an order of magnitude for $z_{0}$ in the case of distributed roughness elements.

The estimated values of $\left|\vec{u}_{*_{c}}\right|$ and those predicted by the model are plotted in Figure 10. The error bars on the estimates are also indicated. In general, the predictability of the $\left|\vec{u}_{\star_{C}}\right|$ values can be done within 10-15 percent and within the error bars on the estimates from the measurements. Figure 10 also indicates the comparison between predicted and estimated values of the apparent roughness. The estimates of the roughness lengths based on the data are inherently noisy; in spite of this, the model predictions and estimates are in good agreement.

The stress estimates are only slightly sensitive to the angle between the wave and the current, when the angles are less than 45 degrees, as predicted by the model. An improvement of less than 10 percent in $\left|\vec{u}_{*_{C}}\right|$ predicted versus measured occurs by including 

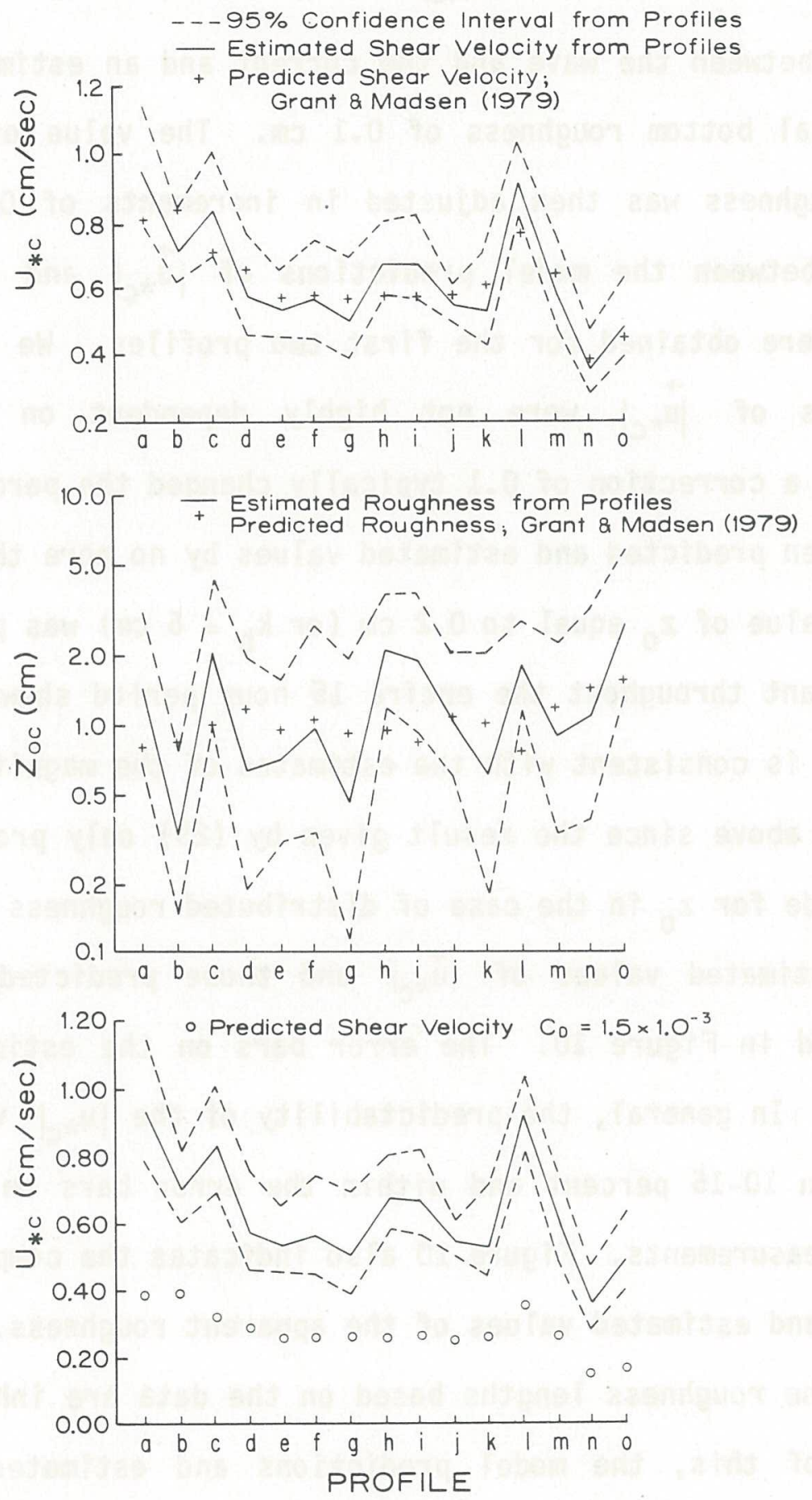

Figure 10: CODE-1 data/model comparison, shear velocity and bottom roughness estimated from measured velocity profiles and predicted by the neutral near bottom model. Also shown is the shear velocity calculated with $C_{D}=1.5 \times 10^{-3}$. 
direction for the range of CODE values. The magnitudes of the values estimated for the physical bottom roughness using (28), are argued to be reasonable through existing laboratory evidence and recent work by Grant and Madsen (1982) in oscillatory flow. Changes in the estimates of the physical bottom roughness of any reasonable number can not explain the roughness values observed in the data. The physical roughness value used in the model runs was kept constant for all the runs (for reasons argued above) and we were able to predict the variation in the apparent roughness values estimated from the data; more evidence for the reasonable estimate of the physical roughness.

In CODE-1 a second tripod was deployed simultaneously within 500 meters of the tripod on which the measurements described here were made. The same results were found to hold for this second tripod. An " even more detailed follow-up experiment (CODE-2) was carried out at the same site in the spring of 1982. Similar results have been found from initial data analysis. Results from the same multi-tripod deployment schemes used in CODE-2 are again consistent for al1 runs examined to date.

Shelf modelers have generally used bottom friction models based upon constant drag coefficients. The usual number employed on the shelf is $C_{D}=1.5 \times 10^{-3}$ (where $\tau_{b}=\rho C_{D}|u| u$ ) as pointed out previously. Figure 10 compares the shear velocity estimated using the constant drag coefficient referenced to the velocity 1 meter above the bottom with the shear velocity values from the profiles discussed here. It is important to note that the velocity must be referenced to a consistent height within the $10 \mathrm{~g}$ layer. Some of the confusion 
on drag coefficient variability existing in the literature can be attributed to inconsistent use of reference velocities (e.g., Winant and Beardsley, 1979). It is also important to note that the apparent qualitative correspondence between the shear velocity estimates from the conventional drag estimate and the data is simply a function of the fact that during the 15 hour period plotted, the relative strength of the waves and currents did not vary greatly. Therefore, most of the temporal variability in the shear velocity, which is caused by the current will be similar in both parameterizations used in Figure 10. However, the magnitude depends mostly on the waves. Other time periods of different relative wave and current activity give different apparent drag coefficients. The results of Figure 10 demonstrate that the drag coefficient must be allowed to vary to reflect the influence of surface waves and that the typical stress values predicted using the constant drag coefficient approach are low by about a factor of four for the relatively mild wave conditions observed during CODE-1.

\section{CODE WINTER STORM DATA}

EXPERIMENTAL SUMMARY

a. Site and F1 ow Description, Measurements

As part of the bottom stress component of CODE, Iong term monitoring of the near bottom flow was carried out at several mid-shelf sites. Long term monitoring of bottom flow in the CODE region was initiated in May of 1979 by the USGS (prior to CODE-1) and lasted 
through May of 1980. The CODE measurements extended this monitoring starting in March 1981 until August 1982. During the nearly two and one half years of measurements, several intense winter storms passed through the CODE site. The bottom flow conditions during these events are quite different than the "everyday" conditions observed for the spring during CODE-1 and described in the previous section. Most importantly, the winter storm conditions include large sediment transporting events with wave formed ripples developing at the seabed and 1arge quantities of suspended sediment occurring. As we described in the introduction, the effect of sediment transport on the bottom stress can be pronounced.

As a result, we describe here a typical storm event from this 2 1/2 year period and evaluate the ability of a bottom boundary layer model to predict the bottom stress, roughness and velocity profile during such a storm event. A station located in approximately eighty four meters of water off the Russian River near R2 (see Figure 1) was maintained during the late fall and winter of 1979 (prior to CODE-1). In December of 1979 a large storm passed through the CODE site while a USGS GEOPROBE tripod (Cacchione and Drake, 1979) was deployed at the station (Cacchione et al., in prep.).

The tripod data set consists of horizontal velocity components ( $u, v)$ measured at $20.3,51.4,66.7$ and 98.4 centimeters above the bottom using a vertical array of electromagnetic current meters; and pressure, temperature and light transmission monitored simultaneously at 2 meters above the bed. Data bursts consisting of 272 seconds of data, sampled at 0.5 hertz were collected every two hours. Bottom 
photographs to monitor the microtopography were taken every two hours using a camera mounted on the GEOPROBE. Also, a sampling program using box cores, high frequency seismics and underwater T.V. camera surveys was implemented at the site to define the micro- and macrotopography and sediment distribution. This survey shows the bottom at the Russian River site to be very similar to the C3 - 90 meter station where the CODE-1 measurements described above were taken.

\section{b. Processing of Data}

1. Selection: A total of 17 data bursts were selected for detailed analysis as was done for the spring ' 81 CODE-1 data; three data bursts, starting approximately 12 hours before the storm, and 14 bursts during the storm. This selection provided a good range of flow and sediment transport conditions. Before the storm, waves and currents were relatively weak, little sediment transport occurred, and the bottom micro-topography was due to bioturbation, nearly identical to that at the central line site in CODE-1. During the storm, intense sediment transport occurred, large quantities of sediment were suspended above the bed, and the bottom micro-topography was controlled by wave generated ripples and near bed sediment transport.

The selection of the data bursts for analysis for the period prior to the storm could be made by setting a minimum regression coefficient as was done for the CODE-1 spring ' 81 data. During the storm the possibility existed that the large amounts of suspended sediment observed could stratify the near bottom flow. Strong stratification could cause the measured velocity profiles to deviate from a 
logarithmic distribution and hence, a simple minimum regression error criterion could not be used. To establish whether or not stratification did influence the profiles a detailed analysis of the near bottom flow was carried out for the sediment distribution observed at the bed using a boundary layer model (Glenn, 1983; Grant and Glenn, 1983) including stratification in a combined wave. and current flow. The model runs demonstrated that even during peak storm conditions the stratification was not expected to modify the flow except for the possibility of one case were very mild modification of the flow may have occurred. Thus, the neutral boundary layer model could be used for the comparisons with the data and a general criteria for a minimum regression coefficient could be applied. A less rigid error range than that applied in CODE-1 was used to set the minimum regression coefficient because of the short sampling time for the profile averages and because only the lower three current meters were working properly during the storm. This error range was $u_{\star} \pm 35$ percent at a 90 percent confidence level. Three additional profiles during the storm also were accepted at a 60 percent error level to expand the range of conditions tested.

2. Processing data: The 17 burst samples were analyzed to calculate the mean current over 272 seconds at each measurement level by time averaging the velocity measurements. The maximum wave amplitude and average period were calculated from the pressure records. Directional wave characteristics could not be calculated from the spectral analysis techniques utilized in the CODE-1 data due to the short length of the burst sample, so only an estimate of the wave direction could be made 
from the ratio of $u_{w}$ to $v_{w}$. The peak in a histogram of the corresponding angle was taken as the direction for the wave. The top current meter (at 1 meter) was not functioning properly during the storm period and therefore only the lowest three current meters were used in the analysis.

The total suspended load in the water column was calculated using the measurements of light scattering and transmission over the burst period. The calibration for the (transmissometers) optical sensors was based on both laboratory measurements and comparison of in situ water samples and transmissometer measurements taken during non-storm conditions (Drake, personnel communication).

3. Profile analysis, stress and roughness estimates: The velocity measurements were used to construct profiles for comparison with the logarithmic profile described by (3). The profiles were zero shifted $(2.5 \mathrm{~cm})$ as described in the analyses of the CODE-1 data. Values of $z_{0}$ and $u_{*}$ were- calculated from the regression line fits to the velocity measurements using (4).

RESULTS

The estimates of $u_{*}$ and $z_{0}$, along with the corresponding regression coefficients and error bars based on the 90 percent confidence limits are given in Table 3. The velocity profiles are well. described by a logarithmic profile as evidenced by the high regression coefficients, except possibly during the peak of the storm where the profiles may be affected by weak stratification from suspended 


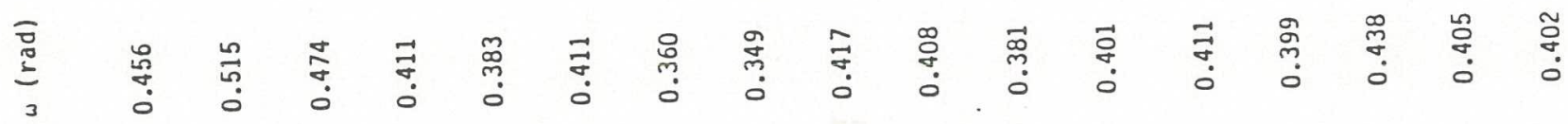
焉

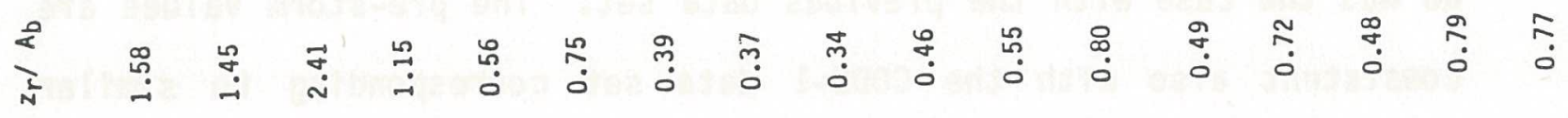

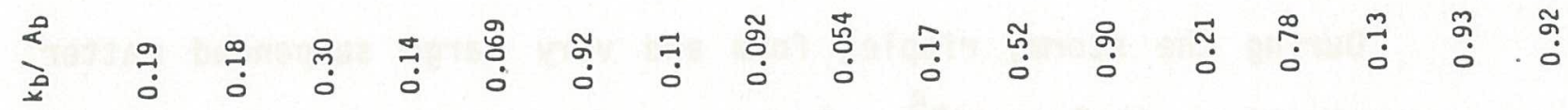

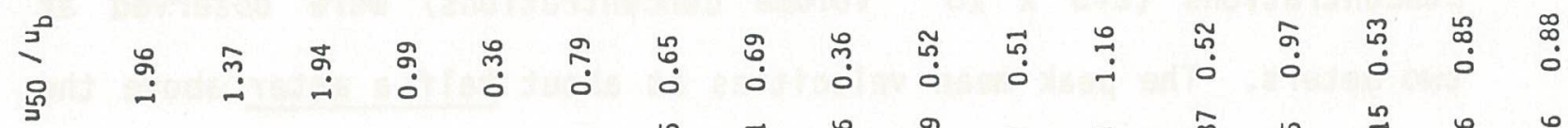

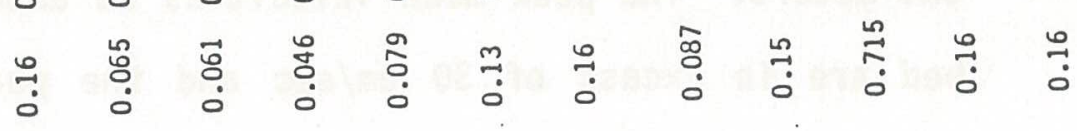

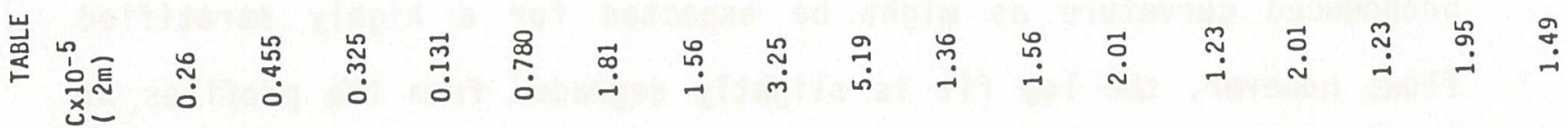

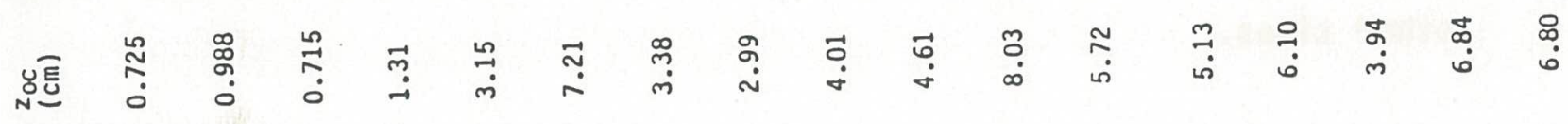

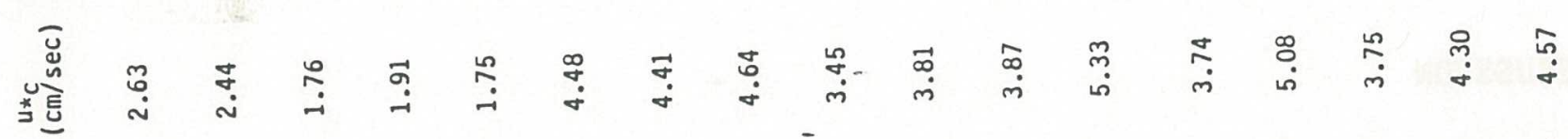


is

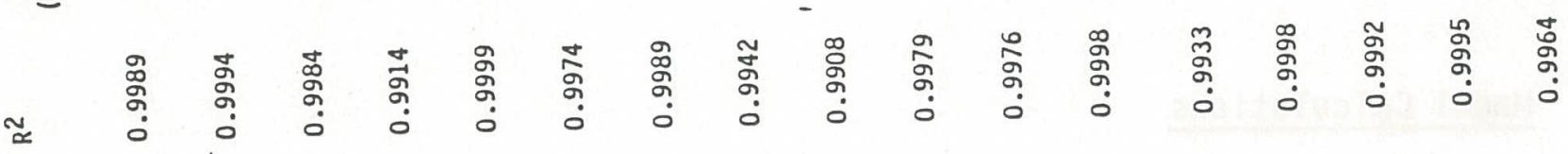

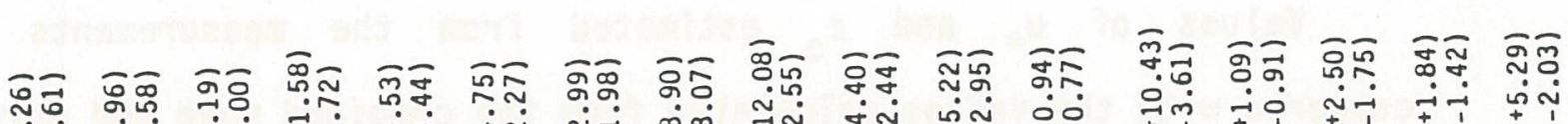

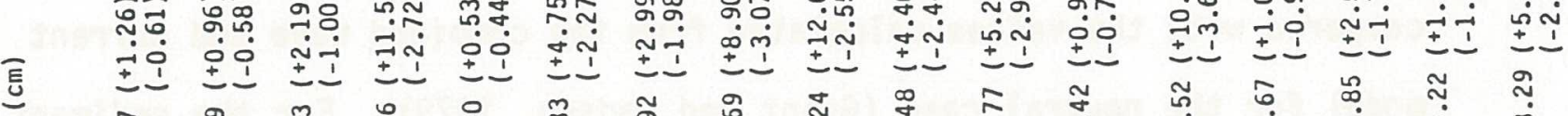

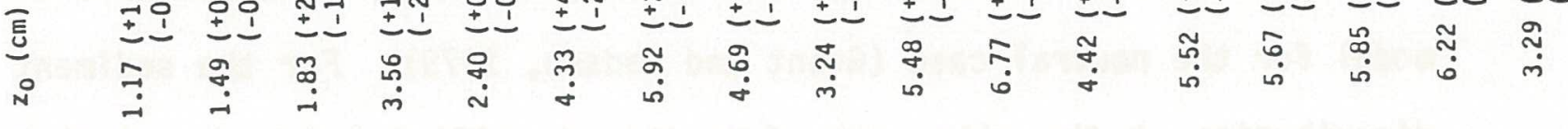

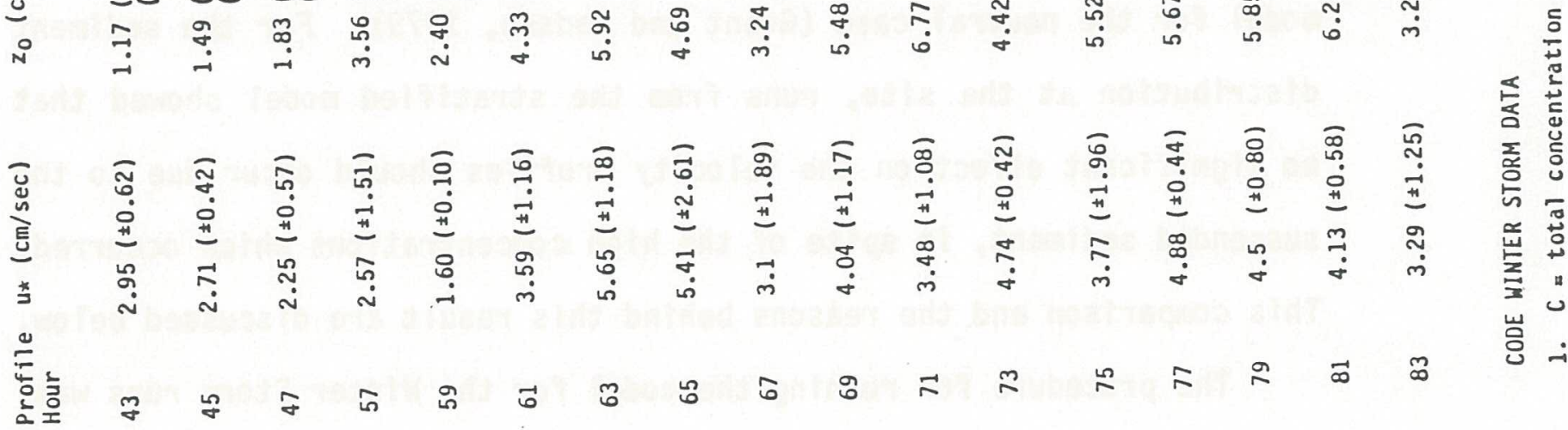


sediment. The values of $u_{\star}$ and $z_{0}$ are seen to be much larger than can be explained by pure steady flow and physical bottom roughnesses as was the case with the previous data set. The pre-storm values are consistent also with the CODE-1 data set corresponding to similar conditions.

During the storm, ripples form and very large suspended matter concentrations $\left(2-5 \times 10^{-5}\right.$ volume concentrations) were observed at two meters. The peak mean velocities at about half a meter above the bed are in excess of $30 \mathrm{~cm} / \mathrm{sec}$ and the peak amplitude of the wave orbital velocity is in excess of $50 \mathrm{~cm} / \mathrm{sec}$ at the same height. Velocity profiles corresponding to this time period still show no pronounced curvature as might be expected for a highly stratified flow; however, the log fit is slightly degraded from the profiles at other times.

\section{DISCUSSION}

\section{a. Model Calculations}

Values of $u_{*}$ and $z_{0}$ estimated from the measurements were compared with the values calculated from the combined wave and current model for the neutral case (Grant and Madsen, 1979). For the sediment distribution at the site, runs from the stratified model showed that no significant effect on the velocity profiles should occur due to the suspended sediment, in spite of the high concentrations which occurred. This comparison and the reasons behind this result are discussed below. The procedure for running the model for the Winter Storm runs was 
similar to that described for the CODE-1 model runs. For the three profiles in the time period prior to the storm (hours 43-47), bottom photographs indicated the bottom was covered with mounds and furrows similar to those at the CODE-1 central line site (analysis of the biota present in box cores shows that the animals at each site are similar, Cacchione et a1., in prep.). Thus, for pre-storm runs the physical bottom roughness was taken as $z_{0}=0.2 \mathrm{~cm}$, i.e., identical to the $\mathrm{c} 3$ (central line) site. During the storm the boundary shear stress was sufficient to erode the bioturbated bottom and put large amounts of silt into suspension; however, the sand component of the silty, sandy sediment moves primarily as near bedload and ripples formed at the boundary. The ripple formation was observed in bottom photographs.

The Grant and Madsen (1982) bottom roughness model for unsteady, oscillatory flow was used in the model runs to predict the ripple geometry, near bed sediment transport and associated roughness (see Grant and Glenn, 1983). The model determines if the ripples are in equilibrium with the local skin friction or if they are decaying through erosion, by calculating an empirically determined separation point for these two regions called the breakoff point. The value of Shields parameter at the break off point, $\psi_{B}$, is given as (Grant and Madsen, 1982)

$$
\psi_{B}=1.8 \psi_{C} S_{\star} 0.6
$$

where $\psi_{c}$ is the critical Shields parameter at initiation of sediment motion

$$
\psi_{c}=\frac{\tau^{\prime} b}{\rho g(s-1) d}
$$


and ${ }^{\tau^{\prime}} b$ is the maximum value of the bottom skin friction, $s$ is the relative sediment density and $d$ is the sediment diameter. In (30) $S_{\star}$ is a dimensionless sediment parameter

$$
S_{\star}=\frac{d}{4 v} \sqrt{(s-1) g d}
$$

in which $v$ is the kinematic viscosity of the water. Once the dynamic ripple range is determined, the empirical expressions given in Table 4 are used to calculate the ripple geometry.

Once the ripple geometry is known the physical bottom roughness is calculated from the expression developed by Grant and Madsen (1982),

$$
k_{b}=160\left(s+\frac{1}{2}\right) d \psi_{c}\left[\left(\psi_{m}^{\prime} / \psi_{c}^{\prime}\right)^{1 / 2}-0.7\right]^{2}+28 \eta \frac{\eta}{\lambda}
$$

The roughness in (33) is made up of two contributions; the first term is the contribution from intense near bottom transport and the second is associated with the ripple geometry where $n$ is the ripple height, $\eta / \lambda$ is the ripple steepness and $\lambda$ is the ripple length.

For the Russian River site the sand component has a peak in the size distribution at $d=0.01 \mathrm{~cm}$. For the model runs $\mathrm{s}$ was taken as 2.65, $v$ as $0.013 \mathrm{~cm}^{2} / \mathrm{sec}$; thus, $S_{\star}=0.0774$. The calculated ripple geometries and roughness lengths are listed in Table 3 along with other input parameters for each profile.

\section{b. Comparison with Model}

The calculated roughness lengths and shear velocities corresponding to the profiles are listed in Table 3. These quantities are plotted along with the calculated 90 percent confidence limits in Figure 11. 
TABLE 4: Empirical Relationships for Ripple Geometry under Waves [Grant et al. (in prep.)]

Equilibrium Range

$\left(\psi^{\prime} / \psi_{C}\right)<\left(\psi^{\prime} / \psi_{C}\right)_{B}$

$n / A_{b}$

$n / \lambda$ $0.22\left(\psi^{\prime} / \psi_{C}\right)^{-0.16}$

$0.16\left(\psi^{\prime} / \psi_{c}\right)^{-0.04}$
Breakoff Range

$\left(\psi^{\prime} / \psi_{C}\right)>\left(\psi^{\prime} / \psi_{C}\right)_{B}$

$0.48 S_{\star} 0.8\left(\psi^{\prime} / \psi_{C}\right)^{-1.5}$

$0.28 S_{\star} 0.6\left(\psi^{\prime} / \psi_{c}\right)^{-1.0}$ 

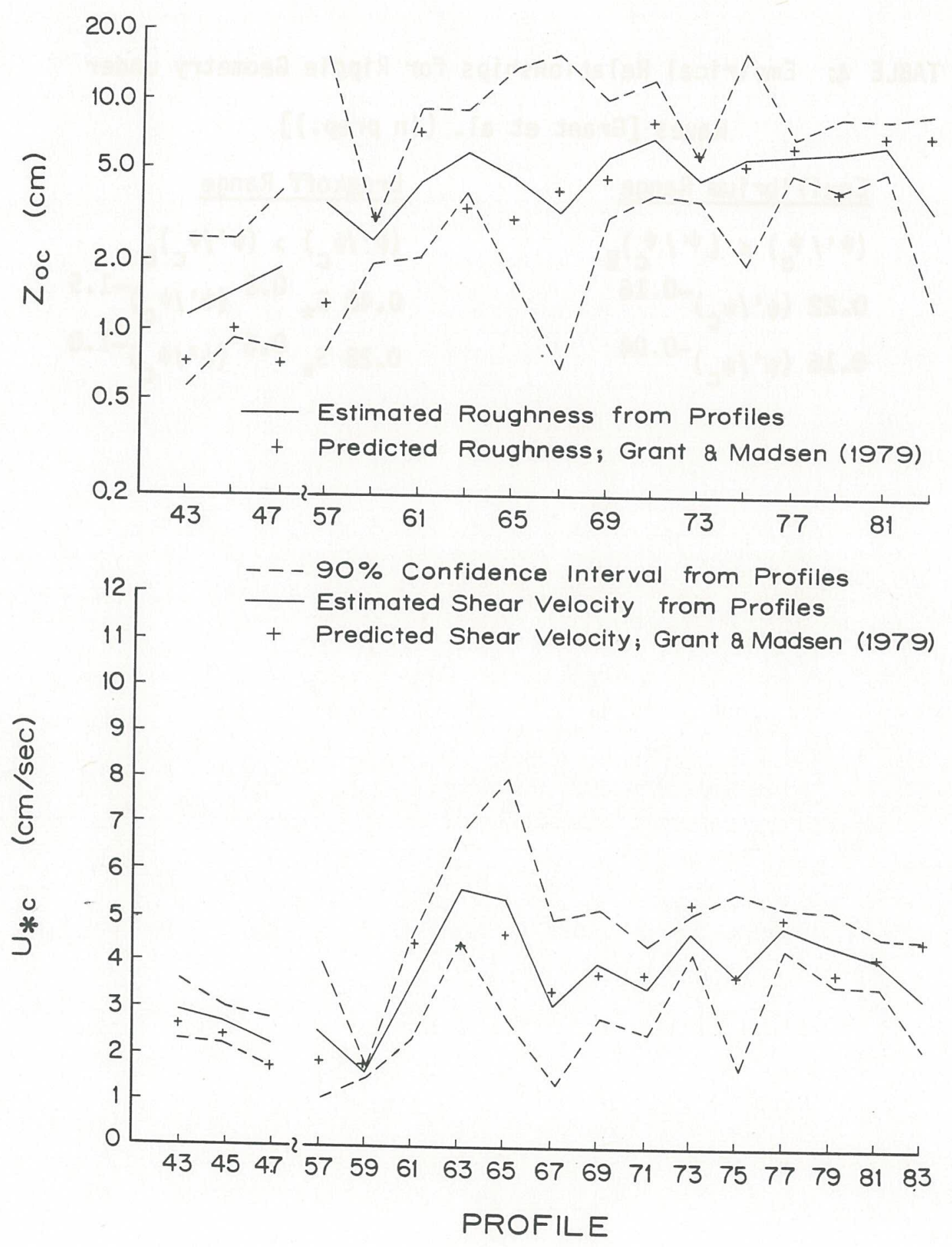

Figure 11: Model versus data comparison for the CODE Winter Storm Data. The break in the plot separates before storm and during storm periods. 
The comparisons are very good in spite of the relatively large suspended sediment concentrations at 2 meters.

The winter storm data set has considerably less detailed support data, relatively short sampling time for each burst and fewer velocity measurements defining the velocity profiles, compared with the CODE-1 data set. For the pre-storm profiles the conditions are very similar to the CODE-1 data where a detailed analyses of the measurements indicated the consistency of the assumption of logarithmic profiles and a constant stress layer. Thus, the high regression coefficients in the Winter Storm data set and the absence of any signs of curvature in the profiles, in spite of having only three points, are strong justification for believing the logarithmic velocity profiles. The shorter time series should only degrade the fits to the 1 og profiles and make $z_{\text {oc }}$ estimates more variable. Thus, we conclude the data set appears to be of good quality for comparisons with the model results.

The storm conditions showed high suspended sediment concentrations, yet no curvature in the velocity profiles was observed except possibly at hour 67, and the profile analysis indicate very good agreement with the neutral model results. This observation is readily explained by using the stratified near bottom model described. in Glenn, (1983) and Grant and Glenn, (1983). The stratified velocity profile above the wave boundary layer has the form

$$
u\left(z_{1}\right)=\frac{\left|u_{*_{C}}\right|}{k}\left(\ln \frac{z_{1}}{z_{O C}}+\int^{z}=z_{O C} \quad \beta d\left(\frac{z}{L}\right)\right)
$$

In (34) the stability parameter $z / L$ is defined as 


$$
\frac{z}{L}=\frac{\kappa\left|\vec{u}_{*_{c}}\right| z}{\left|u_{*_{c}}\right|^{4}} \mathrm{~g} \sum_{n}\left(s_{n}-1\right) c_{n m}(z) w_{f n}
$$

where $C_{n m}(z)$ is the mean sediment concentration at a height $z$ above the bed in size class $n$, and $w_{f n}$ is the corresponding fall velocity for the sediment. Model runs indicate that most of the suspended sediment at the two meter level is silt which has a nearly constant vertical concentration profile in this region. In addition, the fall velocity for the silt is small $\left(w_{f n} \sim 0.05 \mathrm{~cm} / \mathrm{sec}.\right)$. The net result is that the silt does not significantly influence the velocity profile.

The fine sand at the site has a much larger $w_{f n}$, but most of the suspension is close to the boundary where $z$ is small, and it also has little influence on the flow profile. At large boundary shear stress values near the peak of the storm observed concentrations at one meter are 1 ower than predicted by the model. It is likely that some armoring of the bed takes place-in this case. The sand fraction moves primarily as bedload; as more silt is resuspended the relative concentrations of silt and sand at the bed surface change until the surface is composed primarily of the heavier sand fraction. At that point the availability of the silt fraction for resuspension is decreased. The sand fraction cannot be suspended high enough and in large enough quantities to cause significant stratification.

The analysis assumes that at large values of the boundary shear stress the bedforms associated with bioturbation will be eroded, the silt will be put into suspension and the fine sand will be available for bedload transport. Qualitatively, this occurs and is documented 
by bottom camera and underwater television observations; (Cacchione et a1., in prep.). The actual value of the boundary shear stress where this transition occurs from biologically induced bedforms to flow induced bedforms is not well known. Grant et al. (1982) show that a factor of two increase in the stress at initiation of sediment motion can occur in fine sand due to adhesion induced by benthic biota; thus, the transition value is likely a function of the biological conditions. The critical value of Shields parameter is only a question for hours 59-61, since before the storm the boundary shear stress is well below critical values for the sand and for hours $63-83$ the stress is much larger than the critical value.

To address the influence of the bedform transition on the results, model runs were made in the 59-61 hour time period assuming (1) no ripples occurred and the bed remained bioturbated and (2) letting ripples occur at different values of the critical shear stress within a factor of two of the aseptic value. The cases where ripples occurred gave better comparison with the data set. Although good comparisons were found for all values of the critical shear stress within the factor of two range, the best comparison was found for a 20 percent increase in the aseptic value of Shields parameter. This number approaches the error bars on the critical value of Shields parameter for the aseptic laboratory studies of fine sand (Grant et a1., 1982). Thus, it seems reasonable that for the vast majority of the storm flows the influence of biologically induced adhesion on the velocity profile results is minor. 
High quality bottom boundary layer measurements from the CODE site have been analyzed for velocity profiles, roughness lengths and shear stress estimates. Data from typical spring and early summer flows and winter storm flow conditions were examined. The results of the analysis were compared with predictions of Grant and Madsen's (1979) combined wave and current model. The analysis and comparison show for everyday flows:

1. The mean velocity profiles can usually be classified as logarithmic as would be expected for flow over the simple relatively flat bottom at the CODE site. The criteria set for the acceptance of the velocity profiles as logarithmic was a regression coefficient squared in excess of 0.993 and no systematic curvature in the profiles. The deviations from logarithmic mean profiles that occur can be generally attributed to the effects of unsteadiness induced in the averaging process by the presence of weak internal wave velocities. This effect of the waves is argued to be kinematical and does not affect the true form of the mean velocity profile or bottom stress.

2. Power spectral densities calculated for the flows indicate the presence of an inertial sublayer. Independent stress estimates based on dissipation estimates made from the power spectra indicate the presence of a constant stress layer; a result consistent with the log profiles found.

3. The roughness length and shear velocity value estimates for the 
flows are much larger than can be explained by the physical bottom roughness and mean flow alone. Support data on temperature and salinity, suspended sediment, topography and internal waves demonstrates that the observed $u_{*}$ and $z_{0}$ values cannot be attributed to their influence.

4. The remaining factor to explain the value of the estimates is surface waves. Comparisons between data estimates and predictions using the combined wave and current model of Grant and Madsen (1979) show very good agreement between estimated and predicted $u_{*}$ and $z_{0}$ values.

5. The major problem with the prediction scheme is the estimation of the physical bottom roughness over a bioturbated bottom characteristic of the mid-shelf region of the CODE site. Although we can estimate the order of magnitude of the physical bottom roughness, the actual values must be determined empirically. This does not affect the validity of the results, but does complicate-predictions unless bottom photographs or box cores are present.

6. The data and model conclusively show that using the constant drag coefficient approach with a magnitude of $1.5 \times 10^{-3}$ results in under prediction of bottom stress by over a factor of 4 and fails to reproduce the variability in the stress.

The wave and current conditions observed at the CODE-1 site can be considered typical for spring and early summer along the west coast shelf, north of San Francisco. Analysis of year 1 ong records for the coastal wave data network indicates the presence of 1 ong ocean swell during most months of the year. This swel1 is 1 ong enough to reach 
the bottom over most of the shelf. The effects of the waves on near bottom current profile and stress predictions was pronounced even for the gentle wave signal present. Measurements in CODE-2 show stronger mean flows and still indicate a pronounced wave effect.

The Winter Storm measurements are examples of very strong near bottom flows on any open continental shelf. The model predictions are demonstrated to give good estimates of the roughness lengths and shear velocities in these flows in spite of large volumetric concentrations of suspended sediments. The results of an unsteady stratified suspended sediment model (GTenn, 1983; Grant and Glenn, 1983) demonstrate that these velocity profiles are not expected to be modified from the neutral case. Although the data quality is not as high as the CODE-1, C3 data set, the quality is still very good.

We emphasize that the estimates of stress from the data and the model predictions compared to them were for the mean bottom stress influencing the mean velocity profile above the wave boundary layer. This number is crucial to determining the mean friction on the shelf for shelf circulation modeling. It is important to sediment transport calculations in that it controls the mean flow transporting the sediment over most of the bottom boundary layer. It must be emphasized, however, that the instantaneous stress acting inside the wave boundary layer, $0(1-10 \mathrm{~cm}$ thick), is responsible for resuspension of the sediment from the bed. We do not measure this stress value directly in the field but the instantaneous stress is calculated in the model. The point is that care must be used when interpreting stress values estimated in the field. 
The results reported here allow us to make accurate predictions of bottom stress from knowledge of the surface wave climate, water density profile, the bottom characteristics and the current at some level within the bottom boundary layer. An important caveat is that the local topography influencing the current used is simple. This is the case at the CODE mooring sites.

The next step is to look at cross shelf variations in the bottom stress and to determine the horizontal gradients in the stress. The results presented here will help greatly with this task. 


\section{REFERENCES}

Allen, J.S., R.C. Beardsley, W.S. Brown, D.A. Cacchione, R.E. Davis, D.E. Drake, C. Friehe, W.D. Grant, A. Huyer, J.D. Irish, M.M. Janopaul, A.J. Williams and C.D. Winant, A Preliminary Description of the CODE-1 Field Program, CODE Tech. Report No. 9, WHOI Technical Report No. 82-51, 47 pp., 1982.

Bakker, W.T. and Th. Doorn, Near-bottom velocities in waves with a current; 15th Coastal Engr. Conference, pp. 1394-1413, 1978.

Borgman, L.E., Coastal Wave Hydrodynamics, Theory and Engineering Applications, MIT Summer Course, 1976.

Cacchione, D.A. and D.E. Drake, A new instrumentation system to investigate sediment dynamics on continental shelves, Mar. Geol., 30, 299-312, 1979.

Cacchione, D.A. and D.E. Drake, Measurements of Storm generated Bottom

Stresses on the Continental Shelf, J. Geophys. Res., 87, No. C3, $1952-1961,1982$.

Cacchione, D.A., D.E. Drake, W.D. Grant, and A.J. Williams, I I , CODE Geology Report, U.S.G.S. Open File Report (1983).

Cacchione, D.A., D.E. Drake, W.D. Grant, and S.M. Glenn, Near Bottom Flow Measurements in a Winter Storm on the Northern California Shelf (in preparation).

Deacon, E.L., The measurement of turbulent transfer in the 1 ower atmosphere, Advances in Geophysics, Vol. 6, Academic Press, 211-228, 1959.

Donelan, M.A., S.A. Kitaigorodskii, J.L. Lumley and E.A. Terry, Wave turbulence interactions in the upper 0cean, P.2. Statistical characteristics of wave and turbulent components of random velocity field in the marine surface layer, Technical Report, Sibley School of Mechanical and Aerospace Engineering, Corne11 University, 1982.

Glenn, S.M., A Continental Shelf Bottom Boundary Layer Model: The Effects of Waves, Currents and Moveable Bed, Sc.D Thesis, Woods Hole Oceanographic Institution/Massachusetts Institute of Technology Joint Program in Oceanography and Ocean Engineering, WHOI-83-6, 1983. 
Grant, W.D., The influence of internal waves on near bottom velocity profiles measured on the continental shelf: Stress and roughness estimates, EOS Trans. Amer. Geophys. Union, Vol. 63, No. 45, p. 987, Nov. 1982.

Grant, W.D. and O.S. Madsen, Combined wave and current interaction with a rough bottom, Journal of Geophysical Research, 84, (C4), 1797-1808, 1979.

Grant, W.D. and 0.S. Madsen, Moveable bed roughness in unsteady oscillatory flow, Journal of Geophysical Research, 87, (C1), 469-481, 1982.

Grant, W.D., L. Boyer and L.P. Sanford, The effects of bioturbation on the initiation of motion of intertidal sands, J. of Marine Research, Vol. 40 (3), 659-677, 1982 .

Grant, W.D., J.N. Newman, and A.J. Williams, Calibration of an acoustic travel

time current meter for ocean bottom boundary layer studies (in preparation).

Grant, W.D., D.A. Cacchione, D.E. Drake and A.J. Williams, I I , Continental shelf boundary layer measurements in the Coastal Ocean Dynamics Experiment, (in prep.).

Grant, W.D. and S.M. Glenn, A Continental Shelf Bottom Boundary Layer Model; Volume I: Theoretical Development, Technical Report to the American Gas Association, May 1983.

Gross, T.F. and A.R.M. Nowe11, Mean Flow and Turbulence Scaling in a Tidal Boundary Layer, (in press).

Jackson, P.S., On the displacement height in the logarithmic velocity profile, J. Fluid Mech., 111, 15-25, 1981.

Kemp, P.H. and R.R. Simons, The interaction between waves and a turbulent current: waves propogating with the currents, J. Fluid Mech., 116, $227-250,1982$.

Lumley, J.L. Interpretation of Time Spectra Measured in High Intensity Shear Flows. Phys. of Fluids, 8, No. 6, 1056-1062, 1965.

Lumley, J.L. and E.A. Terry, Frequency spectra of frozen turbulence in a random wave field, Technical Report, Sibley School of Mechanical and Aerospace Engineering, Corne11 University, 1982.

Madsen, 0.S. and W.D. Grant, Sediment transport in the coastal environment, Ralph M. Parson Laboratory, MIT Report No. 209. 105 pp., 1976. 
Nagata, Y., The Statistical Properties of Orbital Wave Motions and their Application for the Measurements of directional wave spectra, J. Oceanographic Society of Japan, 19, No. 4, 1964.

Poala, C., Flow and Skin Friction over Naturally Rough Beds, Ph.D. Thesis, Woods Hole Oceanographic Institution/Massachusetts Institute of Technology Joint Program in Oceanography and Ocean Engineering, 1983. Smith, J.D., Modeling of sediment transport on continental shelves, in The Sea, 6, Wiley - Interscience, New York, 1977.

Townsend, A.A., Etrainment and the structure of turbulent flow, J. Fluid Mech., 41, 13-46, 1970.

Williams, A.J. and R. Kochler, An acoustic travel time current meter for ocean boundary layer measurements (in preparation).

Winant, C.D. and R.C. Beardsley, A comparison of some shallow wind-driven currents, J. Phys. Oceanography, $\underline{9}, 218-220,1979$.

Wooding, R.A., E.F. Bradley and J.K. Marsha11, Drag due to regular arrays of roughness elements of varying geometry, Boundary Layer Meteorology, $\underline{5}$, 285-308, 1973. 
Acknowledgement:

The data presented and analyzed here was taken as part of the Coastal Ocean Dynamics Experiment (CODE) Bottom Boundary Layer and Shear Stress Component under the National Science Foundation Sponsorship Grant OCE-8014938. Paul Dragos did much of the programming for the data analysis. Jim Newman, Cindy Pilskaln and Larry Sanford contributed significantly to the data analysis. Chris Dunn provided critical field support. We thank all these people for their assistance. Gretchen McManamin typed the report for which we express our appreciation. Betsey Pratt did the graphics. 



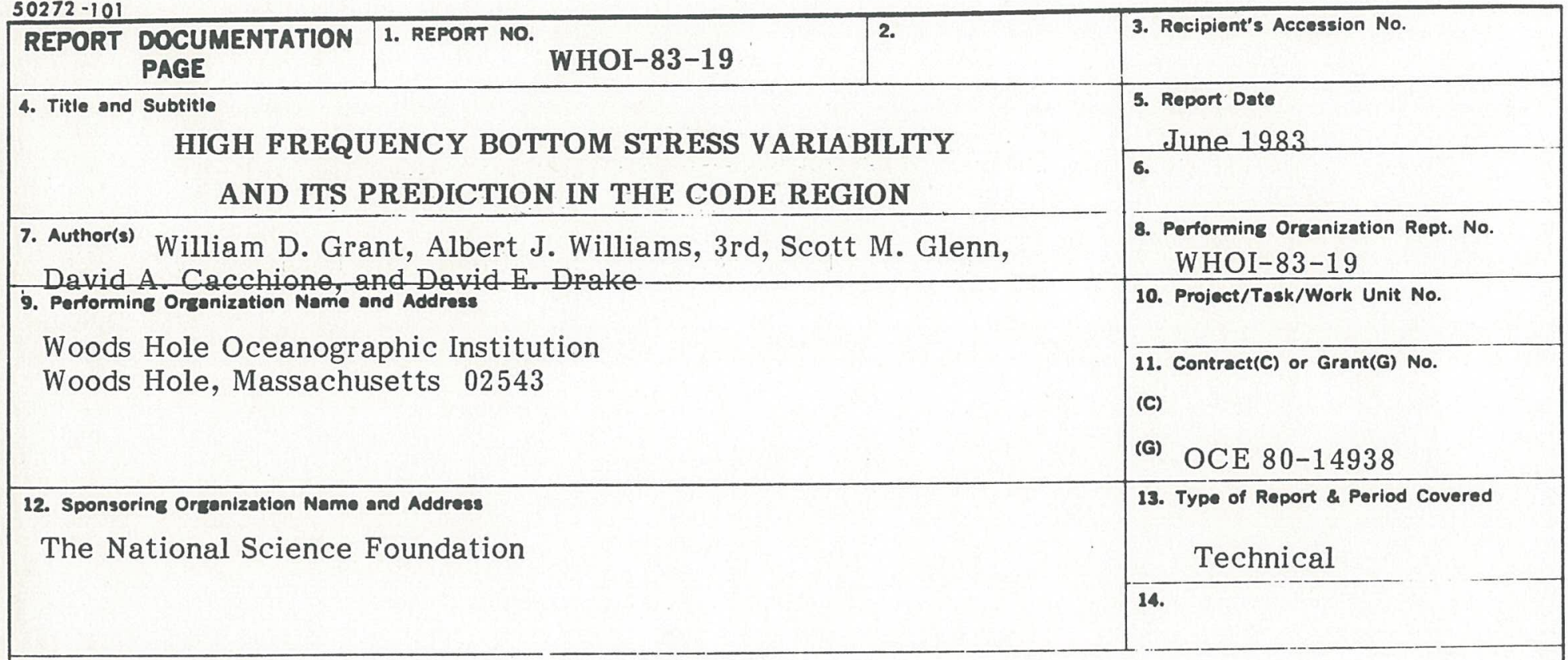

\section{Supplementary Notes}

This report should be cited as: Woods Hole Oceanog. Inst. Tech. Rept. WHOI-83-19.

16. Abstract (Limit: 200 words)

Tripod velocity measurements and supporting data for typical spring conditions and an intense winter storm are analyzed to obtain both velocity profiles and mean bottom stress and roughness estimates. The springtime measurements were taken during CODE-1 at C3 $(90 \mathrm{~m})$ by Grant and Williams, WHOI; the winter storm data was taken prior to CODE at R2 $(80 \mathrm{~m})$ by Cacchione and Drake, USGS. The mean $(<2 \mathrm{~m})$ velocity profiles are generally logarithmic $\left(\mathrm{R}^{2}>0.993\right)$; deviations are primarily due to internal waves. Stress profiles show the logarithmic layer is a constant stress layer. Stress estimates from dissipation and profile techniques agree at $95 \%$ confidence level. $z_{0}$ is an order of magnitude larger than the physical bottom roughness. $u_{*}$ is more than twice as large as given from a usual drag law. These values are demonstrated to be due to effects of combined surface waves and currents (Grant and Madsen, 1979 and Smith 1977). $u_{*}$ and $z_{0}$ predicted by the Grant and Madsen (1979) model are typically within 10-15 percent of the CODE-1 data estimates. Similar results are demonstrated for the winter storm during large sediment transporting conditions. The 14-20 sec. swell influencing the stress estimates are present over most of the year.

17. Document Analysis a. Descriptors

1. Boundary Shear Stress

2. Combined Waves and Currents

3. Moveable Bed Roughness

b. Identifiers/Open.Ended Terms

c. COSATI FIEId/Group

19. Security Class (This Report)

UNCLASSIFIED

20. Security Class (This Page)
21. No. of Pages

72 
